\title{
Effect of gonadal hormones and neurosteroids on injury-induced microglia and astroglia activation
}

Ph.D. Thesis

Andrea Gyenes

Supervisor: Dr. Árpád Párducz

Laboratory of Molecular Neurobiology

Institute of Biophysics

Biological Research Center

Hungarian Academy of Sciences

Szeged, Hungary

2012 


\section{Publication list:}

\section{Papers related to the thesis:}

I. Gyenes A., Hoyk Z., Csakvari E., Siklos L., Parducz A.

17ß-estroadiol attenuates injury-induced microglia activation in the oculomotor nucleus

Neuroscience, 171.677-682. (2010)

II. Hoyk Z, Csákvári E, Szájli A, Kóti J, Paragi G, Gyenes A, Wölfling J, Pfoh R, Rühl S, Párducz A

Computer-aided structure analysis of an epimerized dehydroepiandrosterone derivative and its biological effect in a model of reactive gliosis.

Steroids. 75(3):265-71.(2010) 


\section{Abbreviations}

\begin{tabular}{|c|c|c|}
\hline CA1 & - & cornu ammonis field 1 \\
\hline CA3 & - & cornu ammonis field 3 \\
\hline CNS & - & central nervous system \\
\hline DAB & - & diaminobenzidine \\
\hline DAPI & - & 4'6-diamino-2-phenylindole \\
\hline DHEA & - & dehydroepiandrosterone \\
\hline $\mathrm{E}_{2}$ & - & $17 \beta$-estradiol \\
\hline ER & - & estrogen receptor \\
\hline GABA & - & $\gamma$-aminobutyric acid \\
\hline GFAP & - & glial fibrillary acidic protein \\
\hline ICAM-1 & - & intercellular adhesion molecule-1 \\
\hline iNOS & - & inducible nitric oxide synthase \\
\hline i.p. & - & intraperitoneal \\
\hline LPS & - & lipopolysaccharide \\
\hline MHC & - & major histocompatibility complex \\
\hline ND & - & numerical densities \\
\hline NMDA & - & N-methyl-D-aspartate \\
\hline $\mathrm{ORCH}$ & - & orchidectomized \\
\hline OVX & - & ovariectomized \\
\hline PGE2 & - & prostaglandin enoic acid \\
\hline ROI & - & Region of Interest \\
\hline SERMs & - & selective estrogen receptor modulators \\
\hline TNF- $\alpha$ & - & tumor necrosis factor-alpha \\
\hline
\end{tabular}




\section{Contents}

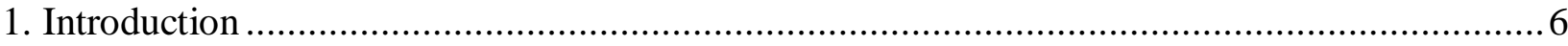

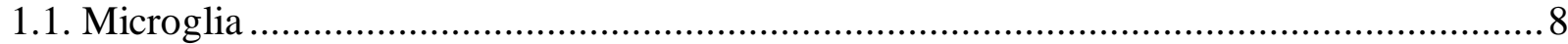

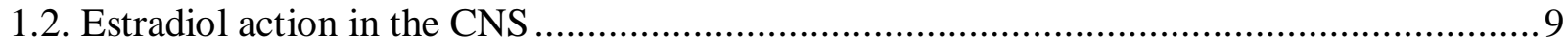

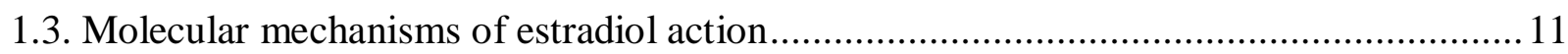

1.4. Possible therapeutic alternatives of estrogen administration ............................................ 13

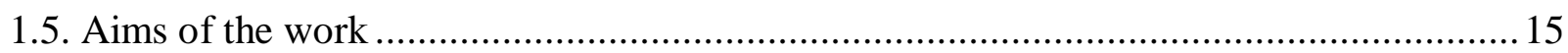

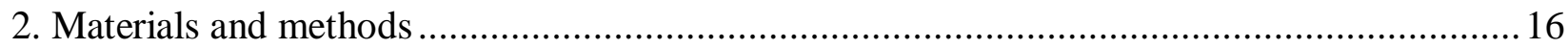

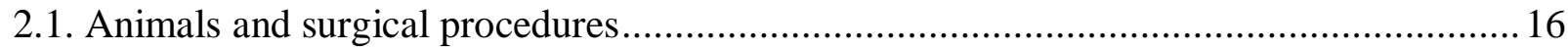

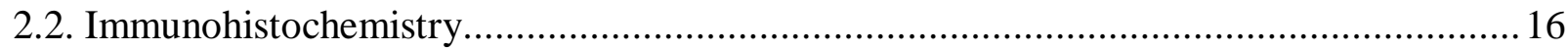

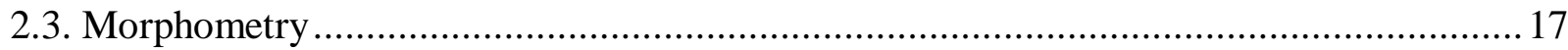

2.3.1. Determination of the increased CD11b immunopositivity...................................... 17

2.3.2. Determination of the number of microglial cells ..................................................... 18

2.4. Western immunoblotting.......................................................................................... 19

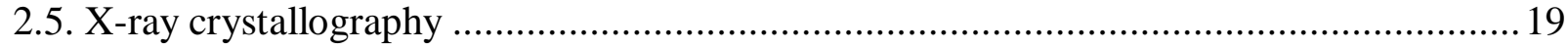

2.6. Molecular modelling calculations................................................................................. 19

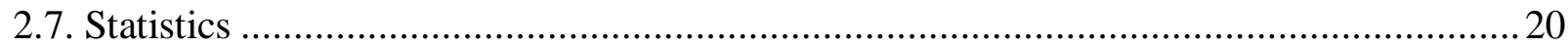

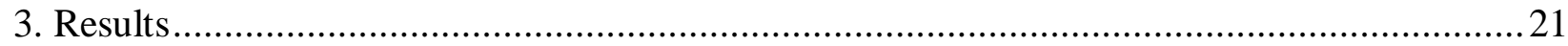

3.1. Injury-induced microglia reaction in the oculomotor nucleus ........................................ 21

3.2. Estrogen treatment reduces injury-induced microglia reaction........................................ 23

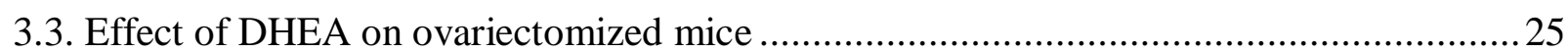

3.4. Sexually dimorphic character of microglia staining in the oculomotor nucleus .................26

3.5. Effects of raloxifen and genistein on microglia activation ............................................. 27

3.6. Immunohistochemical localization of estrogen receptors in the oculomotor nucleus........ 28

3.7. Biological activity of $16 \alpha$-iodomethyl-13 $\alpha$-DHEA derivative under conditions of

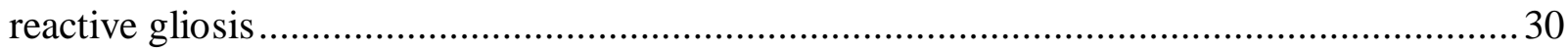

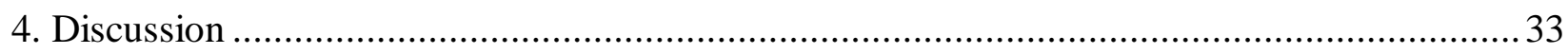

4.1. 17ß-estradiol attenuates microglia activation.................................................................. 33

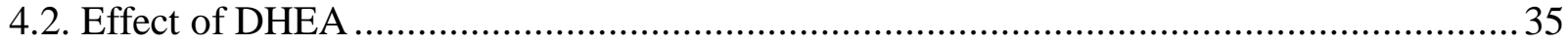

4.3. Sex differences in microglia ..................................................................................... 36

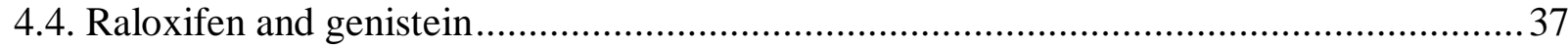




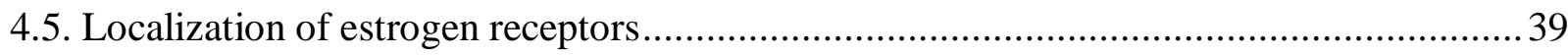

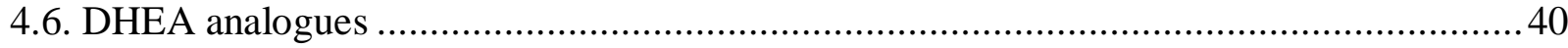

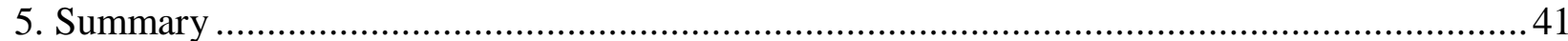

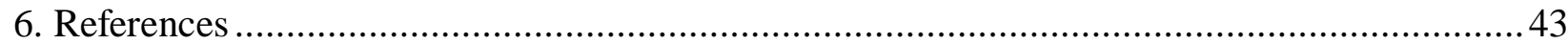

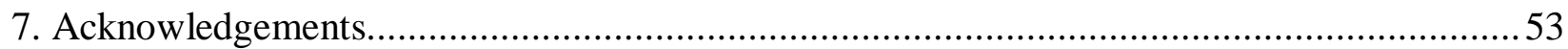

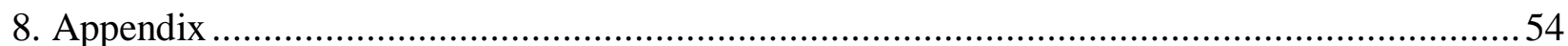




\section{Introduction}

Neurodegeneration and/or injury of the nervous system is a question of fundamental importance and priority in all countries, because among the many diseases affecting human health, disorders of the brain are major causes of mortality and impaired quality of life. The World Health Organisation estimates that more than one billion people are affected by various disorders of the central nervous system (CNS). According to a 2011 study about one-third of the 514 million population suffers from disorders of the brain in Europe (Olesen et al. 2012). The number of diagnoses of brain disorders was $~ 380$ millions, which indicated that many of the affected persons have two (or more) diagnoses. The cost of treatment accounts for approximately $30 \%$ of the total burden of all diseases. In 2010 the EU countries + Norway, Iceland and Switzerland spent 798 billion Euros to cover expenses connected to brain diseases (1550 Euros/capita). With the increasing average life-expectancy this percentage will continue to raise, as the incidence of neurodegenerative conditions increases with age. This is the reason why research focusing on neurodegeneration, neuroprotection and its translation into diagnostic and therapeutic measures is of high priority.

There are numerous possible ways of research strategies which may help us to understand the cellular and molecular mechanisms responsible for the malfunctioning of the diseased nervous system. Although we are talking about neurodegeneration, it has always been generally accepted that in this process not only neurons, but other elements of the nervous system are also affected.

In the last decades, intense research efforts aiming to get data on the function of neuroglia have revealed a number of previously unsuspected features of these cells. They were long considered as relatively passive structural elements of the brain, but on the basis of new results the traditional neuron-centric concept of the CNS has been increasingly challenged. It became quite clear that a plethora of cooperative physiological processes and interactions exists between glial cells and neurons. It became also evident that these reciprocal interactions between glia and neurons are essential for many critical functions both in the healthy and diseased brain.

Experimental and clinical data have clearly suggested that a well defined inflammatory reaction is present in both acute and chronic CNS injuries. In is now generally accepted that 
glia plays active roles in most neurodegenerative diseases and CNS damage is accompanied by reactive gliosis (Marchetti et al. 2005; Marchetti and Abbracchio 2005). It is also evident that inflammatory mediators (thought to be restricted to peripheral immune reactions) are now considered to be part of the pathogenesis of major neurodegenerative diseases. Practically a complete immune system (scavenger receptors, complement system, etc.) has been found in the CNS and is thought to be extremely efficient to fight pathogens and clear cell debris. A complex set of proinflammatory mediators, such as cytokines (eg. interleukin 1-beta or tumor necrosis factor alpha (TNF- $\alpha$ ), cyclooxygenase-2, and inducible nitric oxide synthase (iNOS), are elevated in the cerebrospinal fluid of patients affected by neurodegenerative diseases (Alzheimer's, Parkinson and Huntington's diseases, amyotrophic lateral sclerosis, multiple sclerosis) (Marchetti et al. 2005). The overproduction of pro-inflammatory cytokines together with a variety of highly cytotoxic mediators, including reactive oxygen and nitrogen species may trigger further neuronal damage and increase neuronal vulnerability to cell death (McNaught and Jenner 1999; Bal-Price and Brown 2001; Ekdahl et al. 2003).

Contrary to the generally accepted view that astrocyte response to injury is harmful, accumulating evidence clearly indicates that there is another function of glia. Responding to brain injury astrocytes and microglia act in a very dynamic and cell-type dependent way, they may exert harmful, pro-inflammatory effects (as discussed above), but in certain circumstances they behave as highly protective cells, and exert beneficial (anti-inflammatory) and neurotrophic functions. This behavior possibly depends on the brain region involved, time elapsed, and the given physiological condition, i.e. it is the result of a complex interaction between genetic and environmental factors.

In the present project we focused on the early phase of CNS inflammation and examined some cellular participants and neuroendocrinological features that play a role in it, taking into account possible sexual differences, too. 


\subsection{Microglia}

Microglia comprise a significant proportion in the adult CNS with estimates ranging from 5\% to 20\% (Hanisch and Kettenmann 2007). Microglial cells act as the primary immune effector cells in the brain and they are considered as resident cells of the CNS that are functionally equivalent to macrophages, thus their role includes phagocytosis and antigen presentation (Kreutzberg 1996).

Under normal physiological conditions microglial cells were thought to be quiescent, but the motility of their processes observed in vivo (Davalos et al. 2005; Nimmerjahn et al. 2005) clearly indicates that they are highly active even in resting state. This motility helps the microglial processes to survey their local microenvironment and explains why these cells are the first to sense even a slight disturbance of the brain and are rapidly activated: as a result of inner cytoskeleton changes the cell body becomes enlarged, bearing shorter and thicker cytoplasmic processes (Nolte et al. 1996; Stence et al. 2001). Apart from the high motility of the microglial processes, cells can migrate to the site of injury or toward damaged neurons. In case of focal lesion microglial cells polarize and converge their processes within hours toward the lesion site (Davalos et al. 2005; Haynes et al. 2006). Later they may transform into macrophage-like cells that have phagocytic activity, they engulf toxic molecules and cellular debris (Beyer et al. 2000). Microglia present antigens to infiltrating lymphocytes and play a crucial role in T-cell activation, like other cells of the mononuclear-phagocyte lineage (Cash and Rott 1994). With healing, neural macrophages may either disappear or revert back to quiescent microglial cells (Ladeby et al. 2005).

Microglia can express major histocompatibility complex (MHC) antigens, Fc receptors, complement receptors, $\beta 2$ integrins and intercellular adhesion molecule-1 (ICAM1) in both resting and activated states (Akiyama and McGeer 1990; Bell and Perry 1995; Streit 2002). In response to injury, activated microglia may exert pro-inflammatory effects and can cause neuronal damage and cell death through release of cytokines, chemokines, free radicals, and other small molecules. The products of activated glia are thought to be important for guiding the infiltration of immune cells and for regulating their activities in the nervous tissue (Marchetti et al. 2005). On the other hand, microglia are able to turn into highly protective cells, produce trophic factors and trigger the synthesis of astroglial-derived neurotrophic factors that are essential for promoting neuronal survival, promote axonal sprouting and exert 
anti-inflammatory effects, possibly as a function of time, the brain region involved and as a result of complex interaction between cellular and environmental factors (Streit et al. 2005). This dual profile of microglial reaction may be of practical importance, because by controlling microglial activation it is possible to utilize its therapeutic benefit in treating diseases of the CNS.

Several factors have been shown to interfere with microglia reactions, and sex steroids, in particular estrogen, have also been demonstrated to play a major role in modulating changes of glial reactivity. Alterations of microglia morphology, cell number and immunoreactivity, have been reported to occur, in vivo, as a function of hormonal environment (Long et al. 1998; Mor et al. 1999; Mouton et al. 2002; Lei et al. 2003). These data suggest that microglial cells are targets for steroids and mediate some of the effects of these molecules on neurons, influencing neuroregeneration and the regulation of cell survival (Garcia-Ovejero et al. 2005).

\subsection{Estradiol action in the CNS}

In the last decades we have been witnessing an important change in our approach concerning the biological effects of gonadal hormones. Accumulating pieces of evidence show that sex steroids have more complex function in the brain: beyond their "classical" role in regulating reproductive and/or neuroendocrine events, they participate in brain development and they are also implicated in higher brain functions, such as mood and cognition in adult animals (Garcia-Segura 2008).

The hormones produced by the ovaries and the testis exert a variety of regulatory effects in the nervous system. They influence the development of numerous regions of the brain and the spinal cord, affecting the survival and differentiation of specific neuronal and glial populations as well as the establishment of synaptic connectivity. These hormonal actions result in permanent structural changes of the CNS, providing the morphological background for sexual differences observed in neuroendocrine regulation and behavior. Gonadal hormones are also influencing synaptic and glial plasticity in specific regions of the brain (Parducz et al. 1993; Garcia-Segura et al. 1994) and the spinal cord during puberty and adult life, regulating dendritic morphology, innervation patterns and the number of synaptic 
inputs. Effects of gonadal hormones on synaptic remodeling are well documented in neural circuits that are involved in the control of reproductive and neuroendocrine events. Indeed, there is abundant literature available on the effects of gonadal hormones on the synaptic circuits that control the innervation of muscles involved in copulation and on the brain centers that control reproductive behavior. Experimental data show that gonadal hormones influence synaptic remodeling in brain cognitive regions, such as the hippocampal formation, as well (Leranth et al. 2004; Maclusky et al. 2005).

Estradiol effects on neuronal plasticity after brain injury are well documented. Since the pioneering work of Matsumoto and Arai (Matsumoto and Arai 1979), it has been known that estradiol may promote synaptic sprouting in response to injury. These authors tested the effect of estradiol in the arcuate nucleus after deafferentation, a treatment that results in a loss of axo-dendritic synapses. Treatment with estradiol benzoate for three weeks, beginning on the day of surgery, effectively restored the axodendritic synaptic population of the deafferented arcuate nucleus in adult ovariectomized rats (Matsumoto and Arai 1979; Matsumoto and Arai 1981). Further studies showed that the arcuate nucleus of aged female rats still retains plasticity to react to deafferentation under the influence of estrogen (Matsumoto et al. 1985). Other studies have shown that estrogen enhances synaptic sprouting in the hippocampus of ovariectomized female rats after entorhinal cortex lesions (Morse et al. 1986; Morse et al. 1992) and that estrogen accelerates regeneration rates of axotomized facial motoneurons (Tanzer and Jones 1997; Islamov et al. 2002). Estradiol may influence synaptic sprouting by regulating the expression or activity of a variety of molecules that participate in the process of axonal growth and axonal target recognition, including cytoskeletal components, adhesion and guidance molecules and soluble factors, such as growth factors and neurotrophins. Estradiol induces the expression of the microtubule associated protein Tau in axons (Ferreira and Caceres 1991; Diaz et al. 1992; Lorenzo et al. 1992) and regulates Tau phosphorylation in the brain (Cardona-Gomez et al. 2004; Alvarez-De-La-Rosa et al. 2005; Goodenough et al. 2005) and this may result in the stabilization of microtubules and the promotion of axonal growth. GAP-43 may also be involved in estrogen-induced axonal regeneration. This presynaptic protein is implicated in the growth and regeneration of axons (Oestreicher et al. 1997). The expression of GAP-43 is modulated by estrogen in the mediobasal hypothalamus of adult rats (Lustig et al. 1991), in the preoptic area of developing, 
adult and aged rats (Shughrue and Dorsa 1993; Singer et al. 1996) and in the medial septum and the vertical limb of diagonal band of Broca in aged rats (Ferrini et al. 2002).

Another important action of estradiol on the remodeling of neural tissue under pathological conditions is the regulation of the plastic modifications of glial cells. The effect of estradiol on astroglia is different depending on whether they are acting under physiological or pathological conditions. Thus, estradiol increases GFAP expression and promotes the extension of GFAP immunoreactive processes under physiological conditions, while the hormone decreases GFAP and vimentin expression in gliotic injured tissue (Garcia-Estrada et al. 1999; Ciriza et al. 2004a; Hoyk et al. 2004b). For instance, estradiol decreases astrocyte proliferation and glial scar formation after a stab wound injury in the cerebral cortex and in the hippocampus (Garciaestrada et al. 1993; Barreto et al. 2007), decreases reactive astrogliosis in the hippocampus after kainic acid administration (Ciriza et al. 2004a) and decreases proliferation and increases cell death in primary cortical astrocytic cultures (Zhang et al. 2002).

Several studies have analyzed the effect of estradiol on microglia, in search for a basis for the neuroprotective effects of this steroid and the data show that the hormone exerts well defined anti-inflammatory actions in the brain acting on microglia. (Mor et al. 1999; Vegeto et al. 2006). The hormone reduces the number of reactive microglia in different models of brain inflammation (Vegeto et al. 2003; Vegeto et al. 2006) and brain injury (Barreto et al. 2007) in vivo. It enhances ApoE secretion by microglia in the brain (Stone et al. 1997) and inhibits apoptosis in microglia cultures by a receptor-mediated enhancement of Nip2 protein production (Vegeto et al. 1999). Studies in microglia cultures have shown that estradiol inhibits the induction of iNOS and several other inflammatory mediators in response to lipopolysacharide (LPS) and to pro-inflammatory cytokines (Bruce-Keller et al. 2000; Drew and Chavis 2000; Vegeto et al. 2001; Bruce-Keller et al. 2001; Baker et al. 2004; Dimayuga et al. 2005; Vegeto et al. 2006).

\subsection{Molecular mechanisms of estradiol action}

Although the neuroprotective effects of estrogen are now generally accepted (Gibson et al. 2006) the exact molecular mechanisms are still debated. Earlier studies indicated 
receptor-independent action of estrogen (Culmsee et al. 1999), but recent data clearly suggest the involvement of estrogen receptors (ER) in the process. The general picture became undoubtedly more complicated by the cloning of a second type of ER (Kuiper et al. 1996). At the same time it has become clear that the existence of another receptor with different tissue distribution and different functions makes possible a more sophisticated regulation of molecular events connected with neuroprotection.

The two types of ERs, ER $\alpha$ and ER $\beta$, belong to the nuclear receptor superfamily, they bind $17 \beta$-estradiol and activate several target genes (Kuiper et al. 1996). ER $\alpha$ plays an important role in mediating reproductive functions and the sexually dimorphic effects of estrogens in females; it is highly expressed in female reproductive organs. Although ER $\beta$ is also involved in reproductive functions, it clearly exhibits a distinct distribution pattern. Both receptors are-expressed in the brain too, but their distribution is quite different in specific brain regions (Kuiper et al. 1997; Laflamme et al. 1998). Very few data are available on the expression and functions of $E R \alpha$ and $E R \beta$ in specific subsets of microglia and astrocytes.

According to molecular data the DNA binding domains of ER $\alpha$ and ER $\beta$ are highly conserved ( $98 \%$ ), while their ligand-binding domains exhibit less conservation ( 59\%). It is interesting to note that ER $\alpha$ and ER $\beta$ bind selectively a group of natural, plant-derived and synthetic steroids (Kuiper et al. 1997). This made possible the development of synthetic ligands that exhibit preferential affinity for ER $\alpha$ or ER $\beta$ (Minutolo et al. 2009). By using different model systems (eg. experimental autoimmune encephalomyelitis as an animal model of multiple sclerosis), several laboratories studied the anti-inflammatory effects of estrogens within the CNS (Vegeto et al. 2000; Tiwari-Woodruff et al. 2007a; Gold and Voskuhl 2009). It was shown that estrogen represses certain proinflammatory mediators including chemokines, cytokines, and matrix metalloproteinase-9 in dendritic cells (Gold et al. 2009) and in microglia (Vegeto et al. 2000). This effect has not been observed in ER $\alpha$ knockout mice, which suggests that the protective effect of estrogen is mediated by ER $\alpha$ (Gold and Voskuhl 2009). On the other hand, another research group has reported neuroprotective effects of a ER $\beta$-selective ligand, 2,3-bis (4-hydroxy-phenyl)-propionitrile, but this result may not be clearly associated with anti-inflammatory activity (Tiwari-Woodruff et al. 2007b). 


\subsection{Possible therapeutic alternatives of estrogen administration}

Estradiol is a steroid derived from cholesterol that is produced mainly in the ovary and to a lesser extent in other tissues, including the brain. Estradiol exerts a variety of actions in the CNS, including regulation of neurogenesis, neuronal and glial differentiation, neuronal survival, synaptic plasticity, learning, memory and affective status (Garcia-Segura et al. 2001). The estrogen replacement therapy is proposed for the treatment of different symptoms connected with the menopause, including vegetative nervous disorders, osteoporosis (Lobo 1995) and it has also been shown to have beneficial effect on the circulatory system as well (Schwartz et al. 1995). Many epidemiological studies have pointed to the protective role of estrogen in different neurodegenerative diseases. The incidence and severity of symptoms of Alzheimer`s disease were decreased in women taking the hormone and the therapy improved certain cognitive and motor functions (Fillit et al. 1986; Honjo et al. 1989; Henderson et al. 1994; Schneider et al. 1996; Tang et al. 1996). Although recent data indicate that estrogen replacement therapy is ineffective in patients diagnosed with Alzheimer's disease, it is effective to delay its onset (Henderson et al. 1994; Paganinihill and Henderson 1994; Tang et al. 1996). Inspite of the neuroprotective and pro-cognitive actions of estradiol (McEwen 2002; Resnick et al. 2006; MacLennan et al. 2006; Walf and Frye 2007; Heldring et al. 2007; Young et al. 2007) in rodents and humans, its therapeutic use presents some limitations. For instance, hormonal therapy with estradiol increases the risk of mammary and ovarian cancer and of stroke (Nelson et al. 2002; Beral et al. 2003). Therefore, it is important to examine alternative therapeutic approaches based on the neuroprotective mechanisms of estradiol, while avoiding undesirable peripheral effects of this hormone. Currently three possible alternatives are being extensively studied: i) selective estrogen receptor modulators (SERMs), ii) dehydroepiandrosterone (DHEA), and iii) synthetic derivatives of DHEA.

i) SERMs are compounds that selectively activate ERs in the CNS. The activity of ERs is regulated by its association with transcriptional cofactors that have tissue or cell-specific expression (Klinge 2000; McKenna and O'Malley 2002; Belandia and Parker 2003). This association depends on the tridimensional conformation of the ERs (Norris et al. 1999), which is modified differently by various ER ligands (Brzozowski et al. 1997; Paige et al. 1999), resulting in tissue and cell specific induction or repression of the activity of ERs by SERMs. 
Thus, SERMs either synthetic or natural, such as phytoestrogens, may represent an alternative to estradiol for studying the mechanisms of the neuroprotective effects of the hormone. SERMs may have estrogenic actions in the brain and may lack estrogenic actions, or even possess anti-estrogenic effects in other tissues, avoiding the peripheral risks associated to estrogen therapy. The in vitro studies from the laboratory of Roberta Diaz Brinton at the University of Southern California in Los Angeles (Zhao et al. 2005; Zhao et al. 2006) and from the Cajal Institute using in vivo models of neurodegeneration (Ciriza et al. 2004b; Azcoitia et al. 2006), have shown that some synthetic SERMs, such as tamoxifen, raloxifene or bazedoxifene, and some natural SERMs, such as genistein, are neuroprotective.

ii) DHEA is the precursor of both testosterone and estradiol. It is a known agonist of ER $\beta$ (Chen et al. 2005), and it can allosterically modulate the GABA receptor type A (Genud et al. 2009). DHEA may also exert its effect via conversion to estradiol or to sulfated or hydroxylated metabolites. Its sulfated form (DHEAS) can modulate NMDA (Johansson and Le Greves 2005) and sigma 1 receptors (Zou et al. 2000). Furthermore, its 7alpha- and 7betahydroxylated metabolites may also play a role in its action (Jellinck et al. 2001; Jellinck et al. 2005). DHEA may also act through increasing the level of insulin like growth factor I (Baulieu and Robel 1996). In animal experiments it has been proven to be neuroprotective: in hippocampal primary cultures and in vivo it was able to diminish the toxic effect of kainic acid (Kimonides et al. 1998). According to supporters of DHEA administration, DHEA treatment has several beneficial effects on physical, psychological and cognitive status of both women and men without increasing the risk of any pathological disorder and without causing any endocrine changes (Morales et al. 1994). However, since DHEA can be converted into more potent steroids like androgens and estrogens, caution is needed concerning its administration. In vivo studies showed a positive correlation between DHEA and DHEAS levels and ER/progesterone receptor positive breast cancer (Dorgan et al. 1997; Tworoger et al. 2006). In vitro studies demonstrated that treatment of MCF-7 cell line with DHEA increased the proliferation rate of these cells (Schmitt et al., 2001). Consequently, not only DHEA is being investigated in search of new neuroprotective and/or anti-inflammatory drugs, but efforts are being made to synthesize DHEA derivatives in order to provide the beneficial effects of estrogen action without causing dangerous side effects (Auci et al. 2009). 
iii) Synthetic DHEA derivatives are being produced, but, at least to our knowledge, currently there is only one compound, 16alpha-bromo-epiandrosterone, which has been shown to have biological effects with possible clinical implications. It may be useful in treating progressive pulmonary tuberculosis (Hernandez-Pando et al. 2005), and it may have significant anti-viral activity in experimental feline immunodeficiency virus infection (Pedersen et al. 2003).

Our previous results studying DHEA effect on reactive astrogliosis suggest that DHEA action on injury-induced astroglia reaction is similar to that observed following estrogen and testosterone administration (Barreto et al. 2007), namely, DHEA treatment attenuates astroglia reaction to denervation (Hoyk et al. 2004a). In the present project we investigated the influence of a new synthetic DHEA derivative, 16 $\alpha$-iodomethyl-13 $\alpha$-dehydroepiandrosterone (16 $\alpha$-iodomethyl-13 $\alpha$-DHEA), on reactive astrocytes using the same denervation model.

\subsection{Aims of the work}

The main aims of our studies were the following:

1. To study the effect of $17 \beta$-estradiol on the injury-induced microglia reaction in the oculomotor nucleus.

2. To examine whether the effects of testosterone, DHEA (a testosterone and estrogen precursor), raloxifen (a SERM) and genistein (a phytoestrogen) are similar to 17 $\beta$-estradiol action.

3. To determine the distribution and cellular localization of ER $\alpha$ and $\operatorname{ER} \beta$ within the oculomotor nucleus.

4. To compare the effect of a new synthetic DHEA derivative, 16 $\alpha$-iodomethyl-13 $\alpha$ DHEA, with that of DHEA on reactive astroglia reaction in the denervated olfactory bulb. 


\section{Materials and methods}

\subsection{Animals and surgical procedures}

All animals were raised and maintained on a $12 \mathrm{~h}: 12 \mathrm{~h}$ dark-light cycle in standard laboratory conditions, with tap water and regular mouse chow available ad libitum. During handling of animals, the principles of laboratory animal care (86/609/EEC) were followed.

3-month-old Balb/c mice (20-25g) were gonadectomized $(n=5)$ and two weeks later axotomy/target deprivation was performed by the removal of the right eyeball and the orbital contents including the extraocular muscles. During both procedures deep Avertin (Fluka) anaesthesia was applied. The mice were subcutan injected daily with steroid: $17 \beta$-estradiol (Sigma Aldrich, $5 \mu \mathrm{g} / 100 \mathrm{~g}$ dissolved in sesame oil), testosterone (Fluka, $5 \mathrm{mg} / 100 \mathrm{~g}$ in 20\% $\beta$ cyclodextrin), raloxifen (1.6 mg/kg b.w.), genistein (Sigma Aldrich, $5 \mathrm{mg} / \mathrm{kg}$ b.w.), or DHEA (Fluka, $4 \mathrm{mg} / \mathrm{kg}$ b.w. in 20\% $\beta$-cyclodextrin). The control group received subcutan injections with vehicle.

The chemical deafferentation of the rat olfactory bulbs was achieved by destroying the primary olfactory neurons with $200 \mu \mathrm{l}$ of an aqueous solution of $0.17 \mathrm{M} \mathrm{ZnSO} 4$ administered into both nasal cavities of 3-months-old Wistar rats $(250-300 \mathrm{~g}, \mathrm{n}=5$ per each experimental group). $2 \mathrm{~h}$ following nasal irrigation animals were injected intraperitoneally (i.p.) either with a single dose of 16 $\alpha$-iodomethyl-13 $\alpha$-DHEAd (synthesized at the Department of Organic Chemistry, University of Szeged, $50 \mathrm{mg} / \mathrm{kg}$ b.w.) dissolved in $10 \%$ dimethyl sulfoxide and $20 \% \beta$-cyclodextrin, or with vehicle. The aromatase inhibitor letrozole $(1 \mathrm{mg} / \mathrm{kg} \mathrm{b.w}$.) was injected i.p. $24 \mathrm{~h}$ before $\mathrm{ZnSO}_{4}$ irrigation. After one week of survival animals were sacrificed, protein samples were prepared from the olfactory bulbs and GFAP expression was assessed in Western blots.

\subsection{Immunohistochemistry}

The animals were transcardially perfused under terminal anaesthesia with phosphate buffered saline (PBS; pH 7.4) followed by 3\% paraformaldehyde in $10 \mathrm{mM}$ PBS (pH 7.4). The brains were removed, immersed in the same fixative for 12 hours $\left(4^{\circ} \mathrm{C}\right)$, washed and were 
sectioned through with series of coronal sections $(30 \mu \mathrm{m})$ on a cryostat at the plane of the oculomotor nucleus.

The immunohistochemistry was performed on free floating sections according to the routine $\mathrm{ABC}$ procedure (Gyenes et al. 2010). In the experiments the following antibodies were used: rat anti-mouse CD11b (1:500; Serotec) for microglia, ER $\alpha$ mouse monoclonal antibody (1:500; Vector) and ER $\beta$ rabbit polyclonal antibody $(1: 500 ; \mathrm{H}-150$, Santa Cruz Biotechnology) for detection of the estrogen receptors. Biotinylated secondary antibodies: goat anti-rat IgG antibody (1:800; Vector), goat anti-mouse IgG antibody (1:1000; Vector) and donkey anti-rabbit IgG antibody (1:1000; Jackson ImmunoResearch). The sections were incubated with avidin-biotin-peroxidase complex (1:1600; Vector Elite kit), the reaction was visualized with 5\% 3,3'-diaminobenzidine (DAB, Sigma). After dehydration sections were mounted on silane-coated glass slides and cover-slipped with Entellan (Merck, Darmstadt, Germany).

In the case of immunofluorescence histochemistry the same primary antibodies were used, while secondary antibodies were $1: 100$ DyLight $^{\mathrm{TM}} 549$-conjugated goat anti-rabbit IgG (Jackson ImmunoResearch), 1 : 100 DyLight ${ }^{\mathrm{TM}_{549}}$-conjugated goat anti-mouse IgG (Jackson ImmunoResearch) for $2 \mathrm{~h}$ at room temperature. Nucleus staining was performed in 1:100 000 4'6-diamino-2-phenylindole (DAPI) (Sigma Aldrich) in 0.1 M PB, pH 7.4 for 5 min. Sections were coverslipped with Confocal-Matrix ${ }^{\circledR}$ (Micro-Tech-Lab, Graz, Austria) and examined with a confocal laser scanning microscope (Olympus Fluoview FV1000, Olympus Life Science Europa GmbH, Hamburg, Germany). Microscope configuration was the following: objective lense: UPLSAPO 40x (oil, NA: 1.35); sampling speed: $10 \mu \mathrm{s} /$ pixel; scanning mode: sequential unidirectional; excitation: $405 \mathrm{~nm}$ (DAPI), and $543 \mathrm{~nm}$ (DyLight 549).

\subsection{Morphometry}

\subsubsection{Determination of the increased CD11b immunopositivity}

Activation of the microglial cells after unilateral enucleation was determined as the fold increase of the microglia marker CD11b staining intensity and/or significantly stained area fraction measured at the operated side in relation to the contralateral side. For quantification, a systematic sampling and an interactive, automated image analysis algorithm 
was used, as described by Paizs et al. (Paizs et al. 2009). Briefly, 6 consecutive sections from each series containing the oculomotor nucleus, starting at the most caudal position of the nucleus, were selected for the analysis. Sections were examined in an Olympus Vanox T microscope, equipped with a Spot RT CCD camera, attached to a computer. Images, containing both sides of the oculomotor nucleus in each section were recorded at $1600 \times 1200$ pixel resolution and stored for further processing. Analysis of the staining intensity and the area fraction with immunopositivity was performed with a macro program running in the environment provided by the Image-Pro-Plus image analysis program (ver.5.0, Media Cybernetics) and the Windows XP operating system. Borders of the nuclei of the cranial nerve III at the operated side were first identified, and marked as the Region Of Interest (ROI). A symmetrical area for each ROI at the contralateral side (ROI') was then automatically generated and used as a control to determine the background intensity and for internal reference during calculations. The intensity and the significantly stained area fraction values were determined in each section in the ROI and ROI', which values were then pooled to the animals, to express a single fold-increase value in each animal. The fold-increase values were then averaged in each experimental group.

\subsubsection{Determination of the number of microglial cells}

The numerical density of microglia was determined on CD11b immunostained sections by the unbiased optical disector method (Bjugn and Gundersen 1993). High power images were photographed from the oculomotor nucleus in two different optical planes of a 40x objective lens using a digital camera. The reference plane of the optical dissector was set at near the top of the section and the lookup plane was set at $10 \mu \mathrm{m}$ below (e.g. the disector height was $10 \mu \mathrm{m})$. The images were printed on a laser printer and the analysis was performed with the help of a counting frame $(175 \times 230 \mu \mathrm{m})$. The criteria for counting were that the CD11b stained soma of the microglial cell was in focus in the reference plane and missing or not in focus in the lookup plane within the counting frame. Cells touching the exclusion lines of the counting frame were not counted.

The numerical densities (ND) were evaluated according to the formula:

$$
\mathrm{ND}=\Sigma \mathrm{Q}_{-} / \mathrm{V}_{\mathrm{dis}}
$$


where $\Sigma$ Q. was the number of disector counted cell bodies, $\mathrm{V}_{\text {dis }}\left(175 \times 230 \times 10 \mu \mathrm{m}^{3}\right)$ was the disector volume. There were five mice in each experimental group and three sections/animal were counted.

\subsection{Western immunoblotting}

The protocol described elsewhere was used with some modifications (Hoyk et al. 2004a). Nitrocellulose membranes (Schleicher \& Schuell) containing the blotted protein samples were incubated overnight at $4^{\circ} \mathrm{C}$ with a monoclonal anti GFAP antibody (1:60 000; Sigma), $\beta$-actin (1:5000; Sigma, overnight $\left.4^{\circ} \mathrm{C}\right)$ was used as loading control. Protein bands were detected using a chemiluminescent ECL assay kit. Autoradiographic films were analyzed with the Image Pro Plus 6.2 software. The results from each membrane were normalized to the $\beta$-actin values.

\subsection{X-ray crystallography}

X-ray diffraction studies were accomplished with a Siemens SMART 6000 area detector system (radiation: $\mathrm{Cu} \mathrm{K \alpha}, \lambda=1.54178$ Á). Data collection, cell refinement and data reduction were carried out with Stoe X-Area. The structure was solved with program SHELXS-97 and it was refined with program SHELXL-97. X-ray crystallography was performed in collaboration with professor Rühl at Georg August University, Göttingen, Germany.

\subsection{Molecular modeling calculations}

Two-step analyses were performed to explore the conformation space of the molecules. First, 500 geometries were generated by simulated annealing using molecular mechanics level of calculation with the amber9 program package. Taking the lowest energy conformations, a quantum mechanical optimization was performed using Gaussian 03 code as the second step. The optimization was always followed by a frequency calculation for the sake 
of checking the minima of the final structure. Molecular modelling calculations were carried out in collaboration with Dr. Gábor Paragi from the Supramolecular and Nanostructured Materials Research Group of the Hungarian Academy of Science at the University of Szeged.

\subsection{Statistics}

Statistical analysis of the morphometry data was performed by 2-way ANOVA using the Statistica for Windows program (StatSoft). The normalized data obtained from Western blots were analyzed using one-way ANOVA followed by Tukey test. A P value of less than 0.05 was considered significant. 


\section{Results}

\subsection{Injury-induced microglia reaction in the oculomotor nucleus}

We analyzed the morphological characteristics and the extent of microglia activation in the oculomotor nucleus in an in vivo animal model of motor neuron injury. The animals were killed at different time points after unilateral lesion of the oculomotor nerve and the microglia reaction was quantified in every group.

$\mathrm{CD} 11 \mathrm{~b}$ immunostaining performed on coronal cryostat sections at the level of the oculomotor nucleus clearly shows a homogenous, even distribution of microglia. A multitude of microglial processes extend over non-overlapping territories, thus covering the entire area. There was no difference in either the numerical density or the morphology of microglia between the right and left side of the oculomotor nucleus.

Following unilateral injury of oculomotor axons we could observe a time dependent increase of immunostaining in control ovariectomized mice, which indicates the activation of microglia in the affected area (Figure 1.).
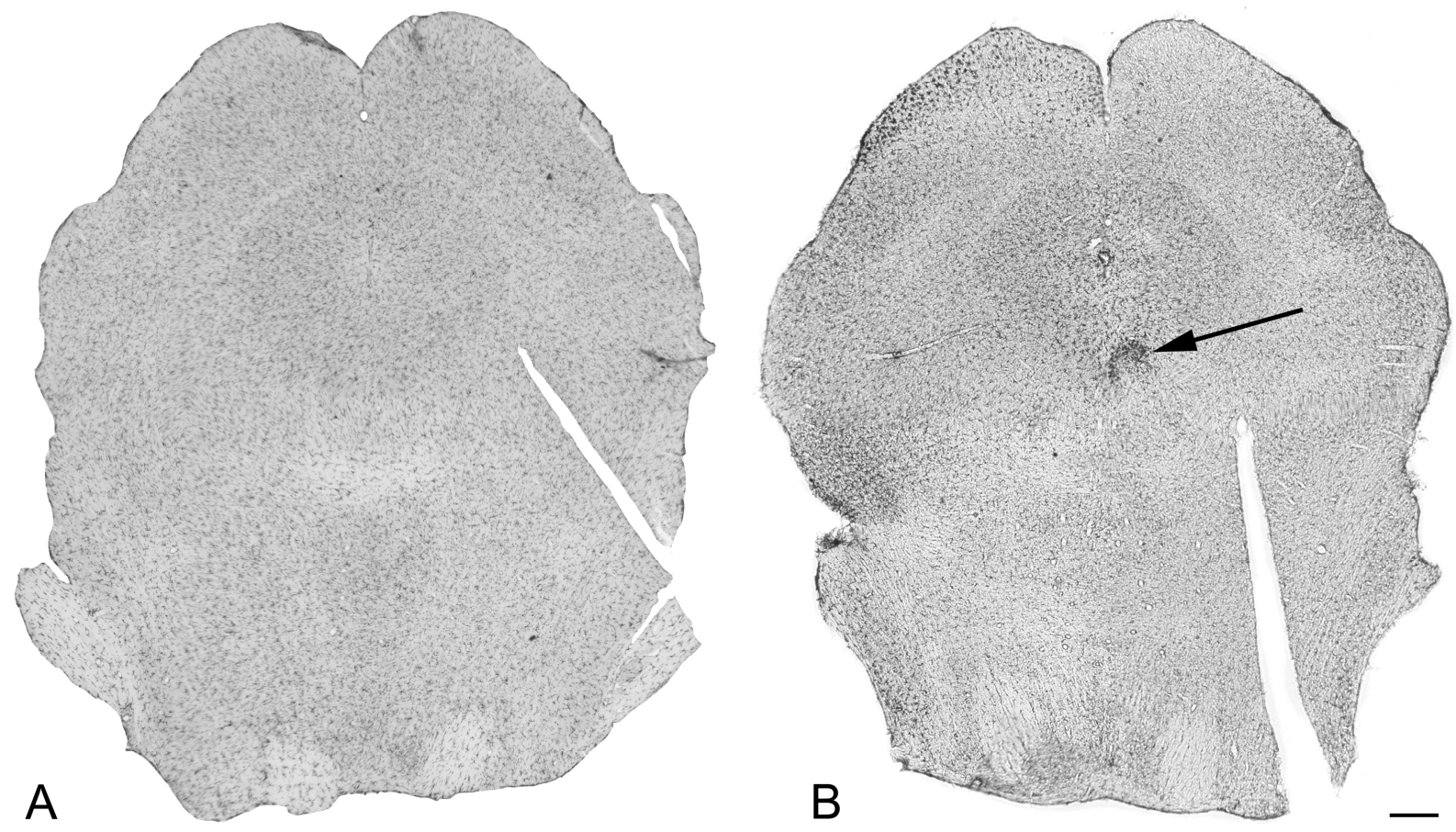

Figure 1. CD11b-stained coronal sections of the mouse midbrain at the plane of the oculomotor nucleus from control (A) and operated (B) animals. Four days after axotomy the affected nucleus displays increased immunoreactivity (arrow). Scale: $200 \mu \mathrm{m}$ 
As shown in higher magnification (Figure 2.) this activation was restricted to the oculomotor nucleus and reached its maximum at 4 days following axotomy. It was maintained at high levels at 4-8 days after the nerve injury before returning to baseline in about three weeks (Figure 3.). Taking into account the time course of the microglia reaction, we focused on the $4^{\text {th }}$ post-operative day in all further experiments studying the influence of various compounds on microglia reactivity.
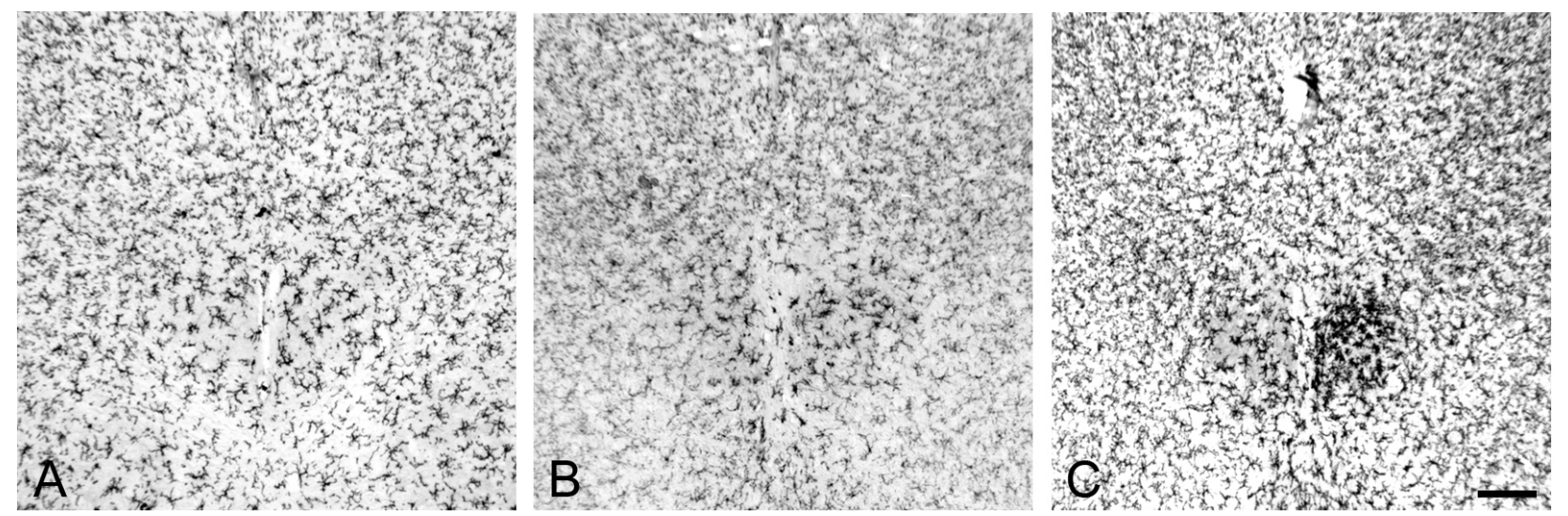

Figure 2. Microglia activation at the $1^{\text {st }}(\mathrm{A}) 2^{\text {nd }}(\mathrm{B})$ and $4^{\text {th }}$ day $(\mathrm{C})$ after unilateral injury. Note the time dependent changes in staining intensity Scale: $100 \mu \mathrm{m}$

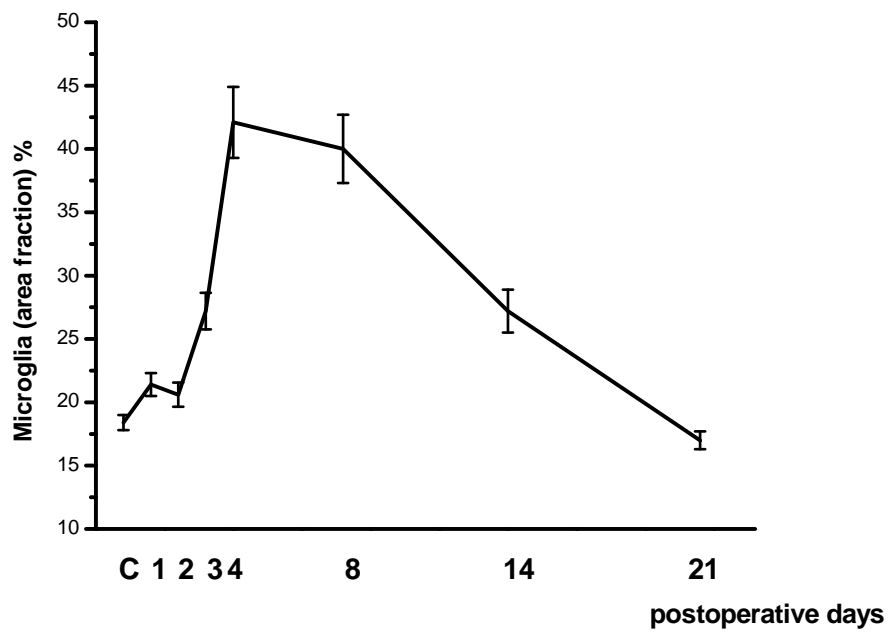

Figure 3. Time course of injury induced microglial activation in the oculomotor nucleus. 


\subsection{Estrogen treatment reduces injury-induced microglia reaction}

In animals receiving daily injection of $17 \beta$-estradiol $(5 \mu \mathrm{g} / 100 \mathrm{~g}$ b.w.) after unilateral injury, the microglia reaction was following the same time course until day 3 and at the $4^{\text {th }}$ day we observed an attenuation of CD11b immunoreactive structures.

Before axotomy there was no difference in either the numerical density or the morphology of microglia between the right and left side of the oculomotor nucleus; microglia had small cell somata with a few delicate cell processes (Figure 4A and 4D). On the $4^{\text {th }}$ postoperative day the cells displayed the activated bushy appearance with shorter and thicker processes in both control and hormone treated mice (Figs. 4E and 4F). In 17 $\beta$-estradiol treated animals, however, we observed an attenuation of CD11b immunoreactive structures at the $4^{\text {th }}$ day (Figure 4C).
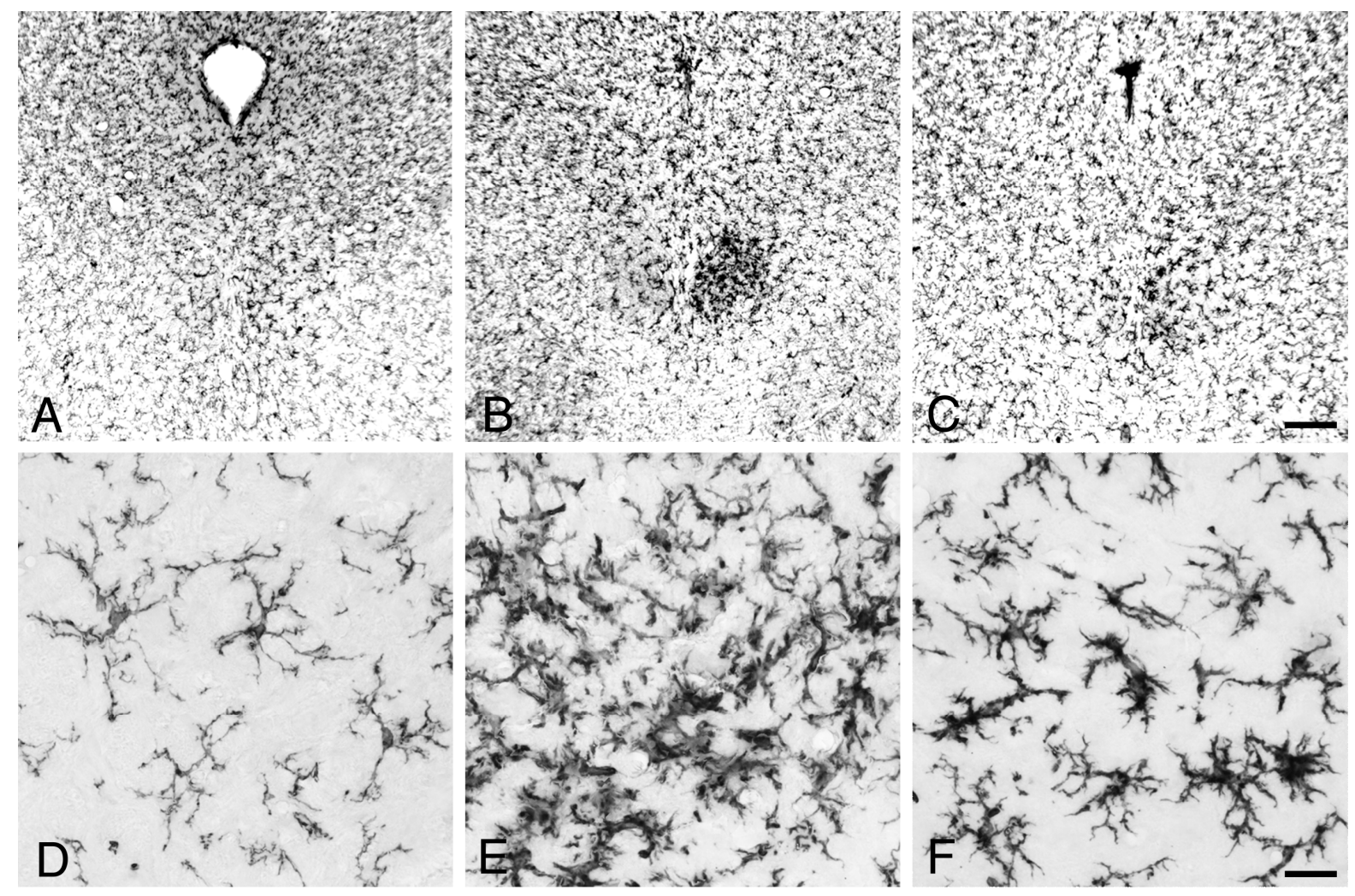

Figure 4. 17ß-estradiol attenuates injury-induced microglia activation in the oculomotor nucleus of ovariectomized mice. In control animals the CD11b immunoreactive cells are evenly distributed (A), they have long branching processes and a small cell body typical of the resting state (D). Four days after axotomy an increased immunoreactivity can be observed in the ipsilateral part of the nucleus of ovariectomized mice (B), the activated cells are of bushy 
character with short and thick processes (E). In animals receiving daily $17 \beta$-estradiol treatment, the microglia reaction is reduced at day $4(\mathrm{C})$, the immunoreactive cells are of activated character (F). Scale: $100 \mu \mathrm{m}(\mathrm{A}-\mathrm{C})$ and $10 \mu \mathrm{m}(\mathrm{D}-\mathrm{F})$.

Quantitative analysis of the CD11b immunohistochemical staining revealed a significantly reduced microglial activation after enucleation in estrogen treated ovariectomized mice at postoperative day 4 compared to the non-estrogen-treated, enucleated group of animals (Figure 5.).

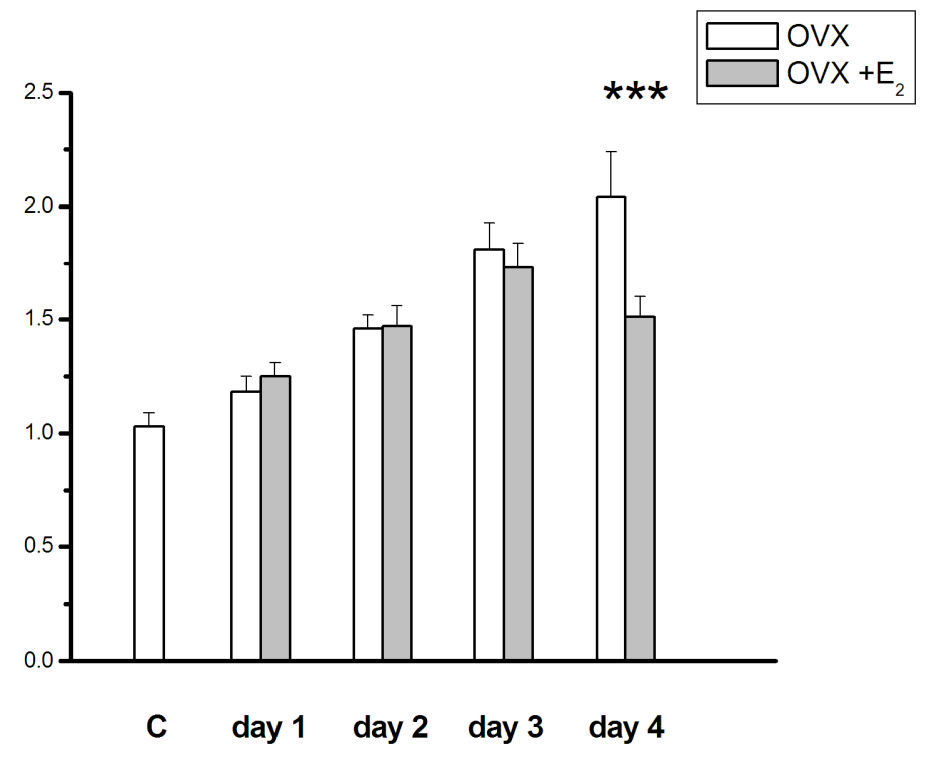

Figure 5. Microglial activation at the operated side of the oculomotor nucleus is expressed as a fold-increase of the CD11b immunopositive area fraction at the ipsilateral side relative to the contralateral side. In unoperated mice this ratio equals one (column $\mathrm{C}$ ). The microglial activation, characterized by the CD11b immunopositive area fraction was significantly reduced in the $17 \beta$-estradiol-treated mice compared to the ovariectomized animals lacking hormone treatment by day 4 after operation $(* * * p<0.001)$.

Following axotomy an increase in the numerical density of labeled microglia was also found on the operated side which became significant on day 4 in control mice lacking $17 \beta$ estradiol. In animals treated with $17 \beta$-estradiol the axotomy-induced increase in numerical density of microglia was significantly smaller at the fourth day compared to the increase in density observed in animals without hormone treatment (Figure 6.). 


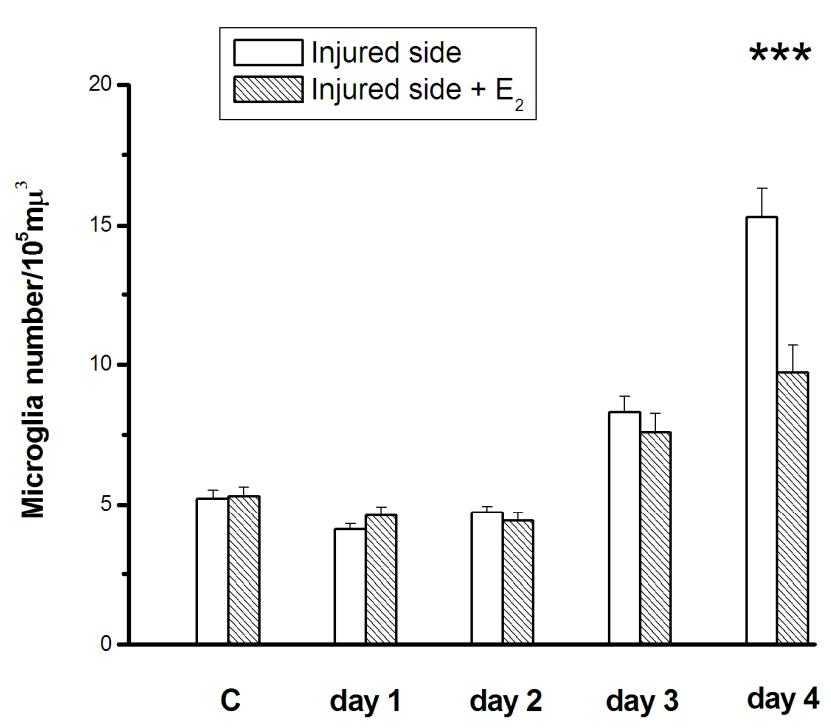

Figure 6. Injury-induced changes in the number of microglia in the oculomotor nucleus. In non hormonetreated animals axotomy results in an increase in the numerical density of CD11b immunoreactive cells on the third postoperative day. At day 4 the number of activated microglia cells was significantly lower in mice receiving a daily dose of $17 \beta$ estradiol as compared to the non-treated animals. $* * * \mathrm{p}<$ 0.001

\subsection{Effect of DHEA on ovariectomized mice}

Although our general aim is to get information on the neuropotective effects of estrogen, for theoretical and practical (clinical) reasons we extended these studies on one of the best known compounds of the neurosteroid family, dehydroepiandrosterone (DHEA). In these experiments we used the same experimental protocol as above, but the animals were treated with DHEA (4 mg/kg b.w. in $20 \% \beta$-cyclodextrin). In the first series of these experiments only female mice were used. As shown in Figure 7., DHEA treatment resulted in a reduction of injury-induced microglia activation. Both the area fraction and the number of microglia cells were decreased. Comparing to estradiol treatment, DHEA has a similar effect on microglia activation.

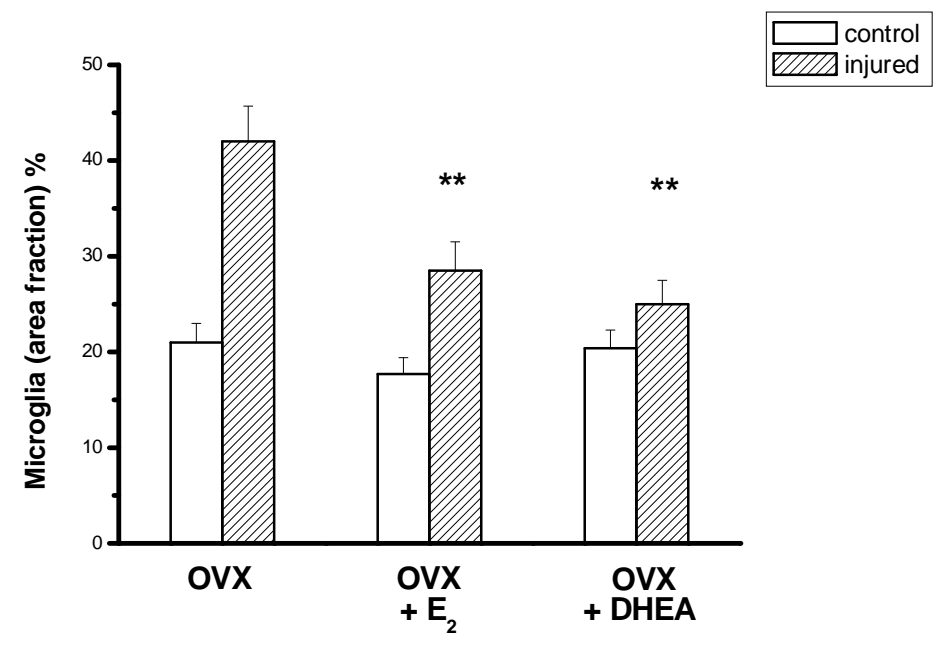

Figure 7. Both $17 \beta$-estradiol and DHEA significantly decrease the microglia activation in ovariectomized mice at the 4th day after injury. $* * \mathrm{p}<0.01$ 


\subsection{Sexually dimorphic character of microglia staining in the oculomotor nucleus}

In other series of experiments we have tested if there is a gender difference in the microglia density of control, non-operated rats and performed morphometric analysis of $\mathrm{CD} 11 \mathrm{~b}$ immunostained cells of intact and orchidectomized males and ovariectomized female mice. We found the highest microglia density in intact males, the value of ovariectomized female group was significantly different (lower), while data from the orchidectomized animals were between the two previous group, not differing significantly (Figure 8.).

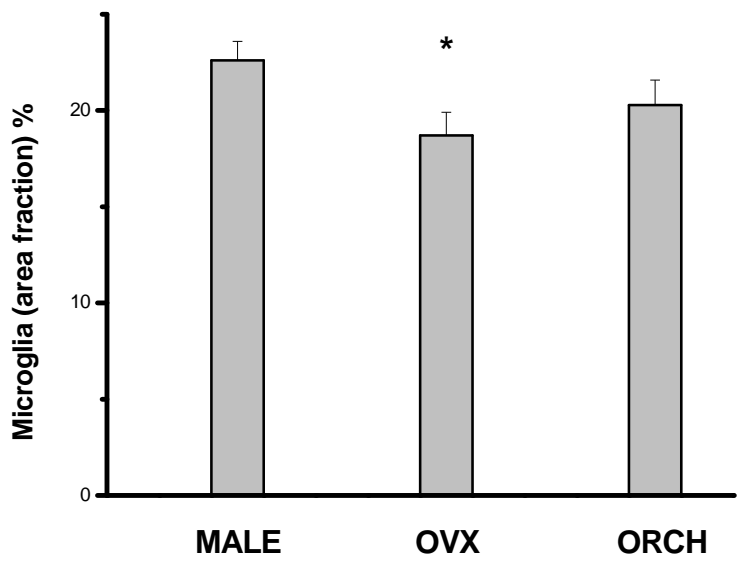

Figure 8. Microglia density in the oculomotor nucleus of control animals. The ovariectomized females differ significantly from the intact male group. * $\mathrm{p}<0.02$ (compared to the MALE group)

In other series of experiments effects of $17 \beta$-estradiol ( $5 \mu \mathrm{g} / 100 \mathrm{~g})$, DHEA (4 mg/kg b.w.), and testosterone $(5 \mathrm{mg} / 100 \mathrm{~g})$ were studied on injury-induced microglia activation in ovariectomized females, orchidectomized males. As in previous experiments, microglial area fractions were compared. It is interesting to note that in orchidectomized males axotomy results in a microglia activation which is less expressed compared to ovariectomized mice, although this difference is not statistically significant. The male gonadal hormone testosterone does not have any effect on the injury-induced microglia activation in neither ovariectomized nor orchidectomized mice. In the orchidectomized group we observed a decrease of reaction in $17 \beta$-estradiol and DHEA treated animals, but the changes were not statistically significant. These results may indicate certain sexual dimorphic pattern, i.e. in males peripheral axotomy tends to induce a less pronounced microglia reaction than in ovariectomized females, and 
estradiol and DHEA treatments also seem to be less effective in reducing microglia reactivity in orchidectomized males as observed at postoperative day 4 (Figure 9.).

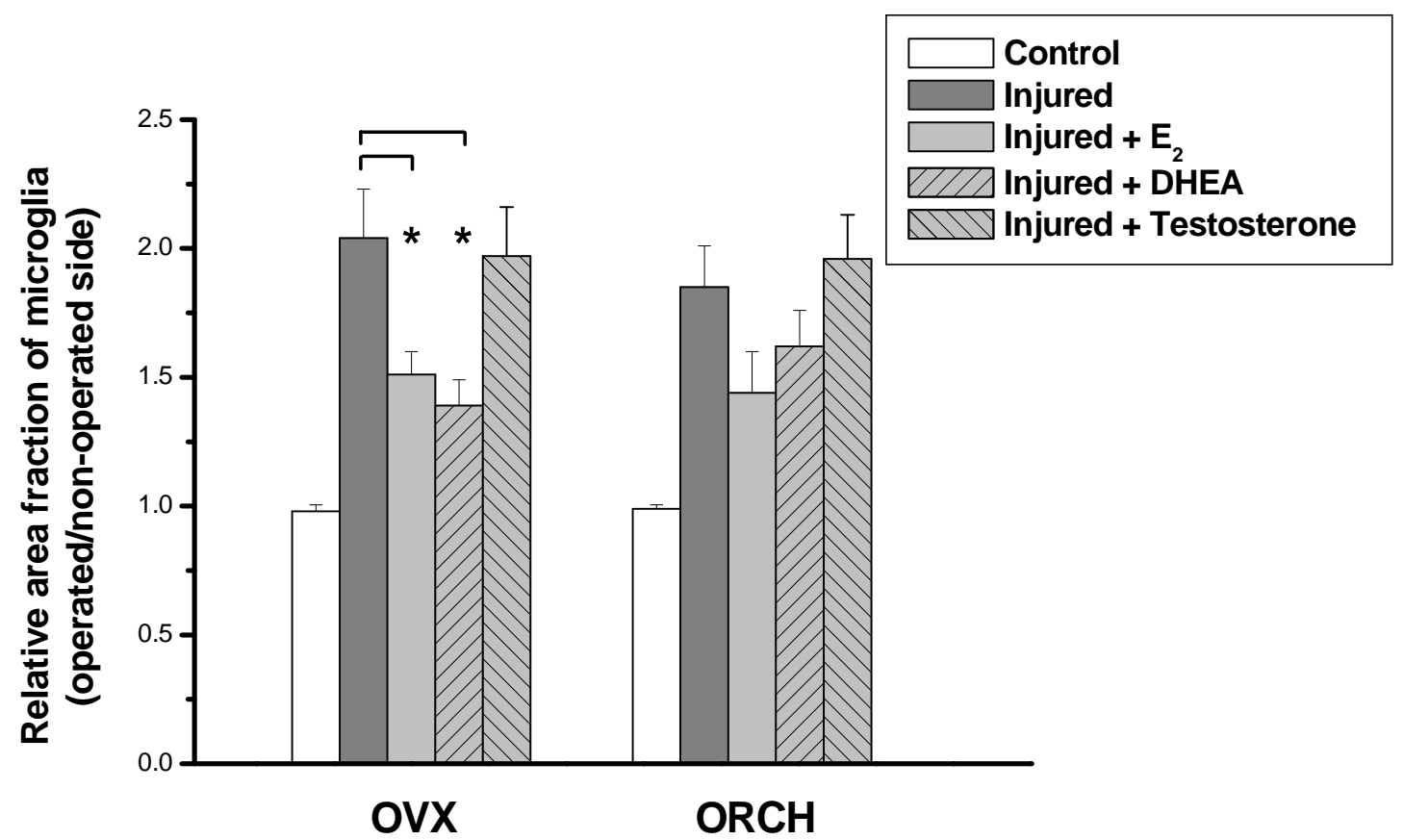

Figure 9. 17 $\beta$-estradiol and DHEA decrease the injury-induced microglia activation only in ovariectomized (OVX) mice. Testosterone treatment does not have any effect on this reaction. $* \mathrm{p}<0.05$ (compared to the injured values)

\subsection{Effects of raloxifen and genistein on microglia activation}

Having established that estradiol and DHEA were able to reduce the injury-induced microglia reaction in ovariectomized mice, in another series of experiments we assessed if other molecules with similar character had any effect in our animal model.

Following injury ovariectomized female mice were injected with raloxifen $(1.6 \mathrm{mg} / \mathrm{kg}$ b.w.), a selective estrogen receptor modulator, and genistein ( $5 \mathrm{mg} / \mathrm{kg} \mathrm{b.w.),} \mathrm{a} \mathrm{phytoestrogen.}$ Using the same protocol we quantified the CD11b immunopositive structures and the data showed that similarly to the effect of estradiol and DHEA, the postoperative treatment of the mice with raloxifen resulted in a significant decrease of activated microglia density (Figure 9.). Genistein did not produce significant effect. 


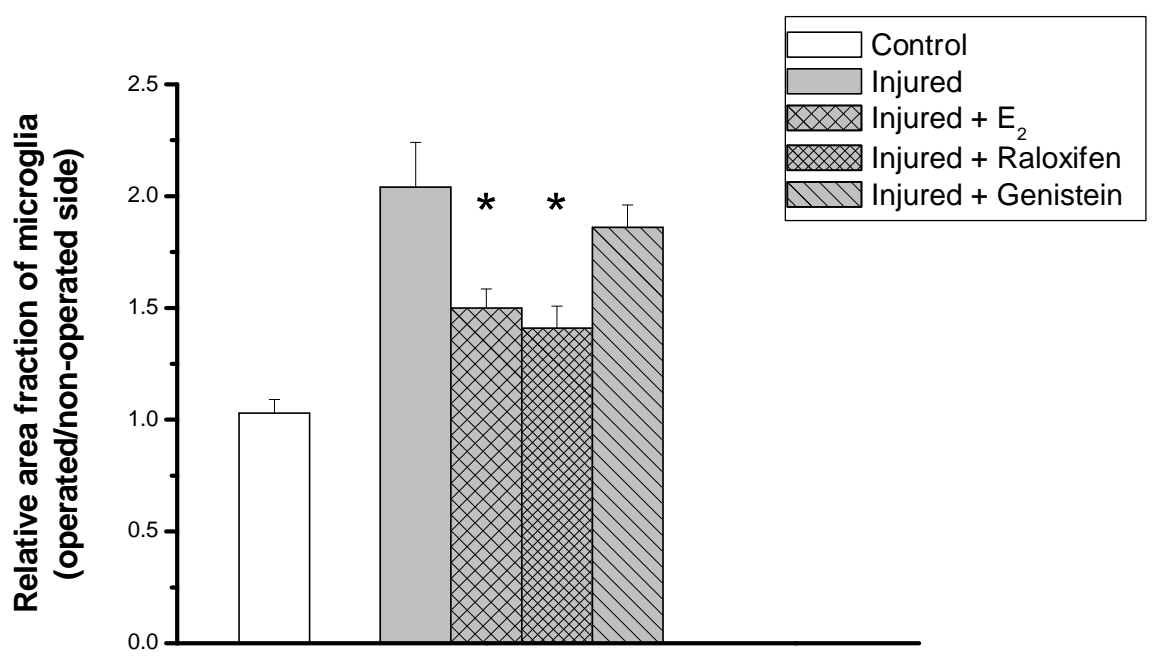

Figure 10 . Similarly to $17 \beta$-estradiol, raloxifen was able to decrease the microglia activation in ovariectomized mice. The phytoestrogen genistein was not effective. ${ }^{*} \mathrm{p}<0.05$

\subsection{Immunohistochemical localization of estrogen receptors in the oculomotor nucleus}

The expression of estrogen receptors in the oculomotor nucleus was explored by immunohistochemistry. Using antibodies of different sources we could not visualize any microglial localization in orchidectomized, intact male or ovariectomized mice, but we found intense staining in the motoneurons indicating the presence of both ER $\alpha$ and ER $\beta$ in these cells. However, the staining patterns of the two receptor types were different. In the case of $\mathrm{ER} \alpha$ the $\mathrm{DAB}$ reaction product was found in the cytoplasm, the nuclei were not labeled, while ER $\beta$ immunostaining showed punctuate staining pattern both in the cytoplasm and in the nuclei (Figure 11-12.). It is important to note that in the neighboring brain areas we could visualize typical nuclear staining of the two estrogen receptor types (Figure 11.). 


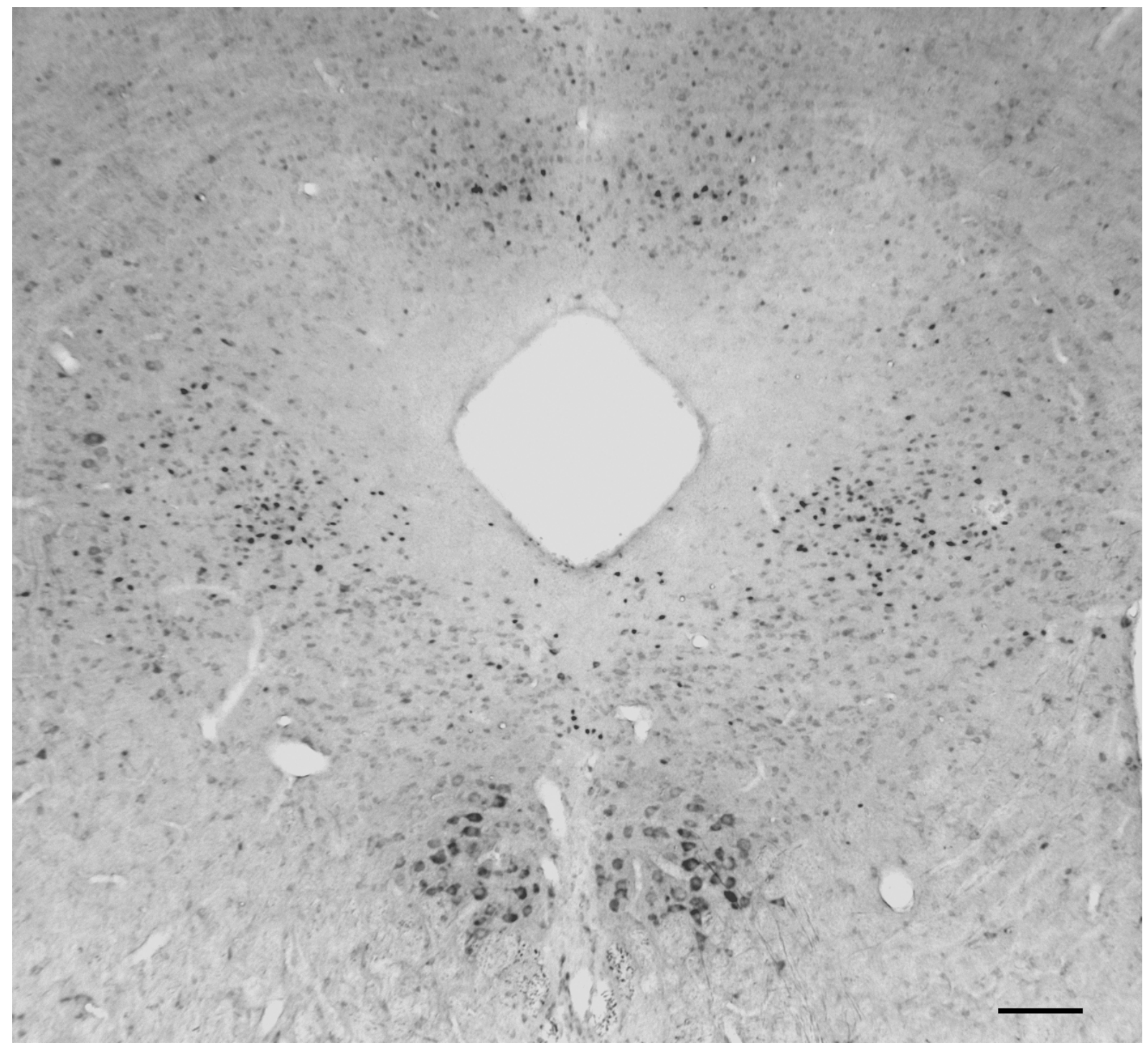

Figure 11. ER $\alpha$ immunostaining of the oculomotor motoneurons. Note the cytoplasmic localization of the electron-dense precipitation, the nuclei are not stained. In the neighboring areas one can see typical nuclear receptor staining. Scale: $100 \mu \mathrm{m}$ 

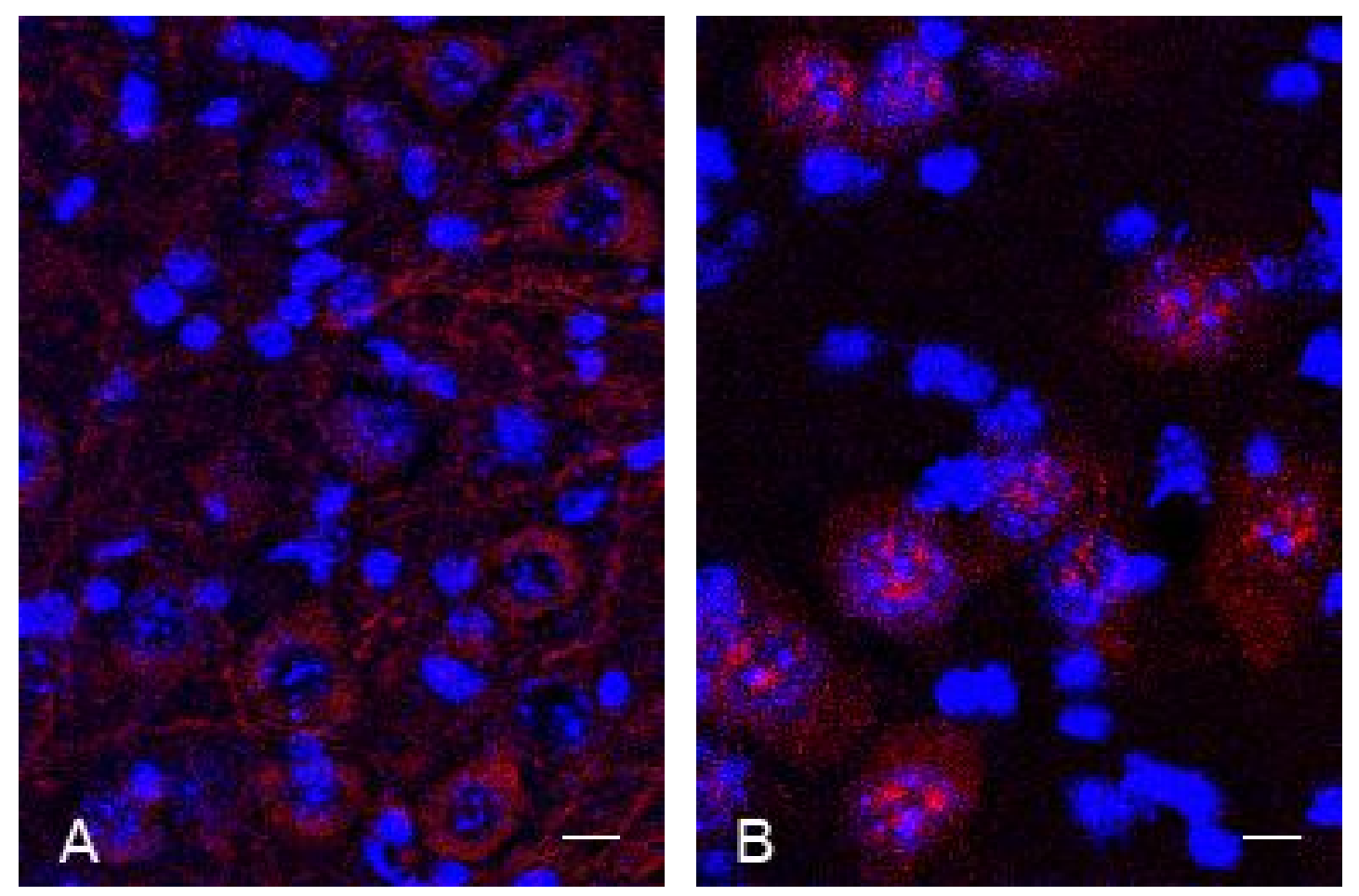

Figure 12. Representative confocal microscopy images of ER $\alpha$ and ER $\beta$ immunostainings in the oculomotor nucleus of ovariectomized mice. A clear difference can be observed between the intracellular distribution of ER $\alpha$ and ER $\beta$ immunoreactivity: ER $\alpha$ immunostaining is present only in the cytoplasm and neuronal processes (A), while ER $\beta$ immunoreactivity product is detected in the nuclei, showing a characteristic punctuate or irregular pattern, and in the cytoplasm (B). Scale: $10 \mu \mathrm{m}$

\subsection{Biological activity of 16a-iodomethyl-13 $\alpha$-DHEA derivative under conditions of reactive gliosis}

Considering the fact that DHEA application in humans needs precaution, effects of a synthetic DHEA derivative, 16 $\alpha$-iodomethyl-13 $\alpha$-DHEAd, on glial reactions were also studied. Our previous experiments showed that DHEA significantly reduced reactive astrogliosis in the chemically denervated olfactory bulb of the rat. As a continuation of these studies we examined the effect of 16 $\alpha$-iodomethyl-13 $\alpha$-DHEAd on GFAP levels using the same model system. Surprisingly, the synthetic DHEA derivative did not reduce the injuryinduced increase in GFAP as observed in western blot experiments. However, when 16 $\alpha-$ 
iodomethyl-13 $\alpha$-DHEAd was applied together with the aromatase inhibitor letrozole, it had the same effect as the natural DHEA.

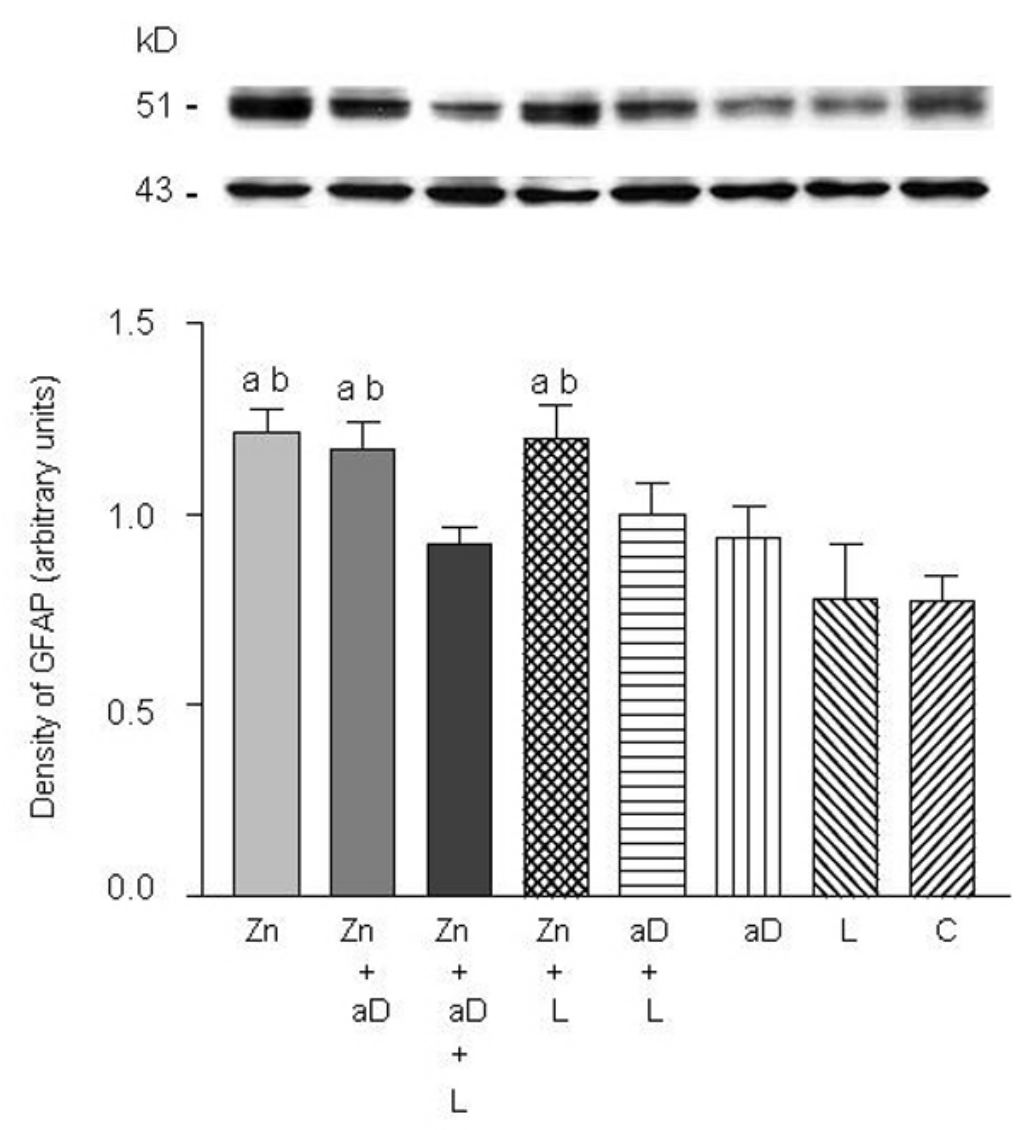

Figure 13. Representative Western blot showing GFAP levels in the olfactory bulb and quantitative analysis of the optical densities of the bands corresponding to each experimental group. $\beta$-actin was used as loading control. GFAP expression is significantly $(\mathrm{P}<0.05)$ increased in animals treated with $0.17 \mathrm{M} \mathrm{ZnSO}_{4}(\mathrm{Zn})$ when compared with controls. This increased GFAP expression is significantly $(\mathrm{P}<0.05)$ reduced in $\mathrm{Zn}$ treated animals after receiving a single dose of $16 \alpha$-iodomethyl-13 $\alpha$-DHEA $(\mathrm{aD})(50 \mathrm{mg} / \mathrm{kg} \mathrm{b.w.)} \mathrm{combined} \mathrm{with}$ the aromatase inhibitor letrozole ( $1 \mathrm{mg} / \mathrm{kg}$ b.w.) (L), while there was no statistical difference between $\mathrm{Zn}$ treated groups that received $\mathrm{aD}$ or $\mathrm{L}$ alone compared with animals that suffered $\mathrm{Zn}$ treatment. Significant changes are indicated compared with control value (a) and value measured in L treated group (b).

This difference in action of the synthetic molecule may result from its 3D structure. Calculating and comparing the molecular structures of DHEA and $16 \alpha$-iodomethyl-13 $\alpha$ DHEAd it could be demonstrated that the epimerization at position 13 introduced during the synthesis of $16 \alpha$-iodomethyl-13 $\alpha$-DHEAd resulted in a bend of the sterane framework, while 
the sterane skeleton of DHEA is nearly planar. This is shown in Figure 14., where DHEA and $13 \alpha$-DHEA are fitted at the $\mathrm{C}(10), \mathrm{C}(5)$ and $\mathrm{C}(6)$ atoms.

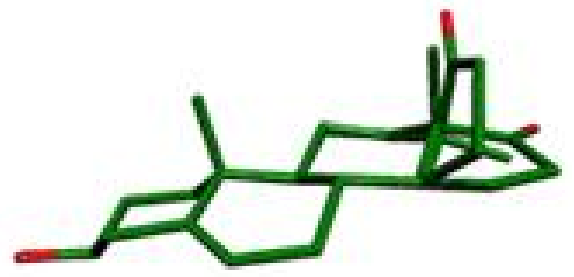

A

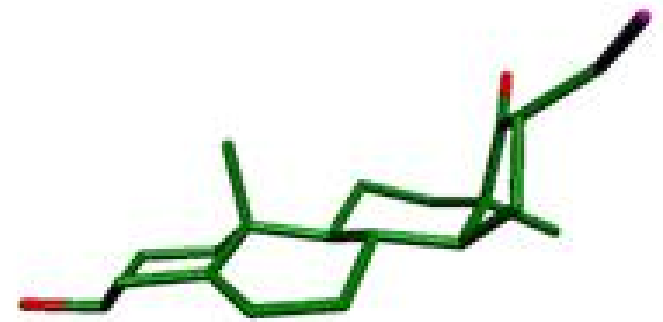

B

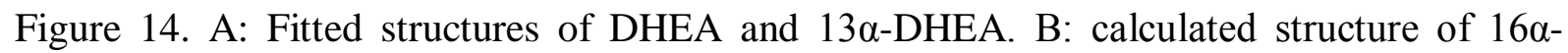
iodomethyl-13 $\alpha$-DHEA derivative. 


\section{Discussion}

\subsection{7 $\beta$-estradiol attenuates microglia activation}

In the present experiments we have used the axotomy model of the oculomotor nerve and investigated the nerve injury induced reactive microgliosis within the oculomotor nucleus. We could demonstrate the morphological signs of microglia activation and proliferation which were affected by $17 \beta$-estradiol.

Changes in CD11b immunostaining intensity have already been observed on the first postoperative day. The morphometric analysis of labeled microglia has indicated an increase of area fraction of immunoreactivity within the injured side of the nucleus, but until day 4 no significant difference was observed between the non hormone-treated and the 17ß-estradioltreated animals. The earliest sign of microglia activation is its morphological transformation, which can be recognized as a partial retraction and a slight hypertrophy of the microglial cell processes. The time course of the microglia reaction observed in the present study is very similar to that reported earlier in different CNS injury models. In a classical model for acute neural injury, the perforant path axonal lesion paradigm (Ladeby et al. 2005), an activated morphology was detected from 12 to $24 \mathrm{~h}$ after the axotomy (Jensen et al. 1994; Jensen et al. 1997) and microglia attained a typical "bushy" character at day 3. These morphological changes were accompanied by an upregulation of CD11b immunoreactivity (Jensen et al. 1997; Jensen et al. 1999). The response reached its maximum between days 5 to 7 after lesioning: at that stage reactive microglia displayed "bushy" morphology, with multiple hypertrophic cellular processes (Jensen et al. 1994; Jensen et al. 1997). In another model, where the injury affected a motor (facial) nerve, the microglia proliferation peaked at day 3 which occurred in parallel with the expression changes, i.e. the upregulation or de novo expression of several marker proteins, e.g., CD11b, complement receptor CR3 (Perry et al. 1985; Graeber et al. 1988), CD4 (Perry and Gordon 1987) and MHC antigens (Streit et al. 1989).

The increased CD11b immunostaining observed on the injured side of the oculomotor nucleus in control animals lacking estradiol may be, at least in part, the consequence of the 
morphological transformation of microglia, triggered by the injury, and the changes in the $\mathrm{CD} 11 \mathrm{~b}$ expression. Moreover, the unbiased morphometric analysis has indicated an increase in microglial cell density, which also can contribute to the more dense appearance of the injured side of the nucleus. This is in accordance with literature data showing that a change in numerical density is one of the characteristic features of the microglia response (Ladeby et al. 2005).

When examining the hormone treated group, quantitative analysis of CD11b immunostaining intensity clearly demonstrates that $17 \beta$-estradiol attenuates the axotomy induced microglial reaction in the oculomotor nucleus. At the same time the unbiased stereological measurements of microglial cell density in the nucleus showed a significant decrease in hormone treated animals 4 days after axotomy. We conclude that microglial response to injury varies according to the estrogenic status and the hormone may be a key factor in the regulation of microglia expression profile in the injured nervous system.

These data support earlier results showing that gonadal steroids exert their antiinflammatory actions in the nervous system by acting not only on neurons, but on nonneuronal cells too, and their main target is microglia (Mor et al. 1999). In different injury models the authors reported microglial activation and cell population expansion which was regulated by estradiol. In rats estradiol decreases microglial reaction induced by the injection of 1-methyl-4-phenylpyridium (Tomas-Camardiel et al. 2002). Lei et al. (Lei et al. 2003) reported that long-term treatment with estradiol reduced the total number of microglia in two regions of the hippocampal formation in aged female ovariectomized B6 mice. The hormone inhibits the proliferation and the activation of cultured microglia (Ganter et al. 1992; Vegeto et al. 2001; Vegeto et al. 2003) and it was shown that estradiol clearly prevented the LPSinduced morphologic reactivity (Vegeto et al. 2003).

Looking for the cellular mechanisms it was found that estradiol enhances apolipoprotein E secretion by microglia in vivo (Stone et al. 1997). Maggi et al. (Maggi et al. 2000) demonstrated that the hormone inhibits apoptosis in microglia cultures by a receptormediated decrease of Nip2 protein production. Studies in microglia cultures have shown that estradiol inhibits the induction of iNOS, and the production of nitric oxide (NO), in response to LPS and to the pro-inflammatory cytokines interferon-g and TNF- $\alpha$ (Vegeto et al. 2000; Bruce-Keller et al. 2000; Drew and Chavis 2000). They have also shown that estradiol 
reduces LPS-induced production of other inflammatory mediators, such as PGE2 and metalloproteinase-9 in microglia culture. These effects are produced also in vivo, and in both cases are mediated by ER $\alpha$ (Vegeto et al. 2001; Vegeto et al. 2003).

\subsection{Effect of DHEA}

Due to its crucial position in the metabolic pathway of the biosynthesis of gonadal steroids DHEA is considered as one of the most important neurosteroid. Our results clearly showed that similarly to $17 \beta$-estradiol it has also attenuated the injury-induced activation of microglia in the oculomotor nucleus of ovariectomized mice.

This is not surprising, because DHEA is regarded as a multifunctional steroid involved in a variety of functions within the CNS and several studies clearly show that it is neuroprotective (Juhasz-Vedres et al. 2006) and may also have a regulatory function in the immune system. However, relatively few experimental data are available about its effects on neuroglia in the CNS. It was shown that DHEA downregulates reactive astrogliosis in adult male rats after a penetrating wound of the cerebral cortex and the hippocampal formation (Garcia-Estrada et al. 1999). Using another animal model of nerve injury our laboratory reported (Hoyk et al. 2004a) that postoperative application of DHEA attenuates astroglia reaction to denervation and may regulate glial plasticity in the olfactory glomeruli of adult rats. It has also been found that DHEA inhibited LPS-induced TNF- $\alpha$ and IL- 6 production in astrocytes (Kipper-Galperin et al. 1999). In an in vivo experiment it was shown that DHEA inhibited the NO production in BV-2 cultures stimulated by LPS (Wang et al. 2001). The author has also observed a decrease of LPS-induced iNOS mRNA and protein levels.

DHEA has an important position in the steroid metabolic pathway and being a precursor of $17 \beta$-estradiol and testosterone it is a relevant question if this neurosteroid has the same effect on activated microglia in both sexes. Analyzing our data we have found a well defined sexually dimorphic character of action: in contrast to the OVX mice, in the orchidectomized animals we could not observe significant attenuation of injury-induced microglia activation after DHEA treatment. It is very important to note that in this animal group $17 \beta$-estradiol produced a more pronounced effect than DHEA, but this was not statistically significant, either. It is worth mentioning that the microglia response to injury is 
somewhat smaller in orchidectomized animals. The male gonadal hormone testosterone was ineffective in both sexes.

\subsection{Sex differences in microglia}

To get further information on this kind of sexual dimorphism we compared the microglia density of the oculomotor nucleus in control (non-operated) mice. We found that in this brain area there is a significant $(\mathrm{p}<0.02)$ difference in microglia density between the male and ovariectomized female animals.

This observation is supported by literature data which show that microglia has many well-known sexually dimorphic functions within the adult rodent brain. Schwarz at al. (Schwarz et al. 2012) demonstrated that the number and morphology of microglia is dependent upon the sex and age of the individual, as well as the brain region of interest. They showed that males have significantly more microglia than females at postnatal day (P) 4, within the parietal cortex, the CA1, CA3 and dentate gyrus of the hippocampus, and the amygdala. In contrast, females have significantly more microglia than males within these same brain regions at $\mathrm{P} 30$ and again at P60. In other regions of the brain, like the paraventricular nucleus of the hypothalamus, no sex differences were found in glial colonization. Nevertheless, they reported that gene expression of a large number of cytokines, chemokines and their receptors shifts dramatically over development, and are highly dependent upon sex, so the sexual dimorphism exists as part of the immune response.

Our present findings indicate a gender difference of microglia staining between ovariectomized and intact male mice within the oculomotor nucleus. Using morphometric analysis of CD11b immunostained cells, we have confirmed the highest microglia density in intact males, the value of ovariectomized female group was significantly lower, while data from the orchidectomized animals were between the two previous groups, not differing significantly. It is important to note that both in intact and orchidectomized males axotomy results in a microglia activation which is less expressed compared to ovariectomized mice, although this difference is not statistically significant. This observation theoretically correlates with other analyses: clear sex differences have emerged in neurological disorders in which the disease mechanisms are accompanied by chronic inflammation, including Alzheimer's disease, Parkinson's disease, stroke, and multiple sclerosis (Turgeon et al. 2006). 


\subsection{Raloxifen and genistein}

Looking for new neuroprotection strategies it is generally accepted that therapies based on estrogen effect are worth considering and experimental data clearly show that estrogen receptors are good candidate targets for protective action. Knowing the unfavorable side effects of hormones, the research is focusing on other molecules acting on estrogen receptors. Both SERMs and phytoestrogens were found to be neuroprotective and some species of these molecule families may represent an alternative to estradiol for the treatment of neuronal damage. This is the reason why we have extended our studies in this direction and tested the effects of the SERM raloxifen and the phytoestrogen genistein on the microglia reaction.

Our results are supporting literature data, because in ovariectomized mice raloxifen produced a significant decrease in injury-induced microglia activation - the effect was in the same magnitude as observed in the case of $17 \beta$-estradiol.

Several laboratories have been studying the effects of SERMs on neuroprotection. In different in vivo models tamoxifen has been shown to decrease the damaged brain area after ischemia (Mehta et al. 2003; Kimelberg et al. 2003), it prevented hippocampal neuronal loss following kainic acid injection (Ciriza et al. 2004b). Using in vitro systems Benvenuti et al. reported that tamoxifen exerted neuroprotective effects against beta-amyloid-induced toxicity in long term neuroblast cell cultures (Benvenuti et al. 2005). Although the authors concluded that the neuroprotective effect of SERMs is direct, in vivo and in vitro studies suggest that microglia may also be involved. Studying the brain of aged animals (female mice) Lei et al. reported that similarly to $17 \beta$-estradiol, long term raloxifen treatment lowered the microglia density in the hippocampus which may indicate the influence of SERMs on the microglia mediated inflammatory processes (Lei et al. 2003). Using primary cell cultures of mouse (N9) and rat (hippocampal) microglia the LPS-induced NO and IL-6 secretion were measured (Suuronen et al. 2005). In these experiments SERMs triggered a significant anti-inflammatory response, while $17 \beta$-estradiol was ineffective, which suggests that the process is not estrogen receptor mediated.

More recently Tapia-Gonzalez et al. used peripheral LPS administration and assessed the microglia activation in the white matter of the cerebellum following immunostaining by major histocompatibility complex-II (MHC-II) (Tapia-Gonzalez et al. 2008). This molecule is 
a good marker of microglia activation - it is practically undetectable in resting microglia, but it is overexpressed in activated cells. The authors demonstrated that LPS treatment resulted in a significant increase of labeled microglia. 17ß-estradiol, tamoxifen and raloxifen treatment reduced the number of MHC-II immunoreactive cells in both male and ovariectomized female rats.

The phytoestrogens are non-steroid molecules synthesized in plants, their molecular structure is very similar to estradiol and they are able to mimic or produce estrogenic or antiestrogenic effects. This is the reason why these compounds are considered as selective estrogen receptor modulators. Genistein is the most intensively studied naturally occurring plant-derived phytoestrogen but the literature data concerning its mode of action are still controversial. Although only a few papers have been published in connection with microglia, most of the studies confirmed their direct or indirect involvement in neuroprotection. In mesencephalic neuron glia and microglia-enriched cultures the primary soybean isoflavone genistein attenuated the LPS-induced loss of tyrosine hydroxylase-immunoreactive neurons. In parallel with these effect the authors measured lower TNF- $\alpha$, NO and superoxid concentrations and they interpret these data as inhibition of microglia activation, which can be a part of the protective mechanism (Wang et al. 2005).

Cortical microglia cultures of ovariectomized rats from anaimals pretreated for two weeks with a mixture of phytoestrogen compounds responded differently to LPS. In control animals the LPS treatment resulted in typical inflammatory microglia response: increase of cytokines TNF- $\alpha$, IL-1 $\beta$, IL-6, and TGF- $\beta$. Cultures from rats receiving phytoestrogen produced significantly lower level of proinflammatory cytokines and higher level of antiinflammatory TGF- $\beta$ (Marotta et al. 2006).

It is known that in diabetic retinopathy the cellular source of increased levels of inflammatory cytokines is the activated microglia. In streptozotocin-induced diabetic Sprague Dawley rats it was shown that genistein effectively reduced the diabetes-induced retinal inflammation. According to the authors genistein interferes with the signaling mechanisms (ERK and P38 MAPKs) of the activated microglia (Ibrahim et al. 2010).

In our injury model the phytoestrogen genistein proved to be ineffective, it did not attenuate the microglia activation. On the basis of literature data in the present experiments we used $5 \mathrm{mg} / \mathrm{kg}$ b.w. genistein and our result supports the observation of Azcoitia et al. (Azcoita 
et al. 2006) who were studying the neuroprotective effect of soy phytoestrogens and genistein. They reported that soy extract at a very wide dose range (1 to $20 \mathrm{mg} / \mathrm{kg} \mathrm{b.w.)} \mathrm{prevented}$ neuronal loss induced by kainic acid. Genistein, however, showed neuroprotective effects only at high dose $(10 \mathrm{mg} / \mathrm{kg})$, which may indicate that other components in the soy extract are responsible for the neuroprotective effect. We plan further experiments to determine the doseresponse curve of genistein in our system.

\subsection{Localization of estrogen receptors}

For the understanding of the molecular mechanisms involved in the estradiol effect on microglia, it is important to know if it is mediated by estrogen receptors. Previous studies have reported the presence of ERs in microglial cells of different brain areas, in microglia cell lines and in primary microglia cultures (Vegeto et al. 2001; Baker et al. 2004; Dimayuga et al. 2005). Both ER $\alpha$ and ER $\beta$ are expressed in the microglia of the CNS, but their distribution in different brain regions is not fully explored. Interpreting the results of several studies on the protective effect of estradiol, the involvement of both receptor subtypes is evidenced (Baker et al. 2004; Tapia-Gonzalez et al. 2008).

In the oculomotor nucleus we could visualize both $\mathrm{ER} \alpha$ and $\mathrm{ER} \beta$, but the distribution pattern was somewhat surprising. The microglial cells were not labeled, the immunoreaction was detected exclusively in motoneurons. This suggests that estradiol action on reactive microglia is a complex phenomenon, it is mediated indirectly, through neuron-microglia communication. The staining pattern of the two ER subtypes in the motoneurons is different, ER $\alpha$ is localized in the cytoplasm, while ER $\beta$ shows a characteristic punctuate staining pattern mostly in the nuclei and, to a lesser extent, in the cytoplasm. In the cerebellum of the rat a similar punctiform ER $\alpha$ staining pattern was described (Tapia-Gonzalez et al. 2008) and the authors reported an intensification of staining after LPS administration. In our model injury did not influence the intensity of ER staining.

The presence of both ERs in the motoneurons suggests that estradiol may trigger different signalizing pathways and induce expression of different genes in the same type of neurons depending on the type of receptor activated, which altogether may lead to the 
enhancement of signals that calm microglial reaction. However, this possible mode of estradiol action on reactive microgliosis needs further investigation.

\subsection{DHEA analogues}

When analyzing the mode of action of DHEA, there are several possibilities that have to be taken into account, such as acting through conversion into androgens and/or estrogens (Akwa et al. 1991; Zwain and Yen 1999), and acting directly on GABA receptor type A (Perez-Neri et al. 2008) or through its sulfated form on NMDA or sigma 1 receptors (Zou et al. 2000; Johansson and Le Greves 2005). Little is known, however, on the mechanisms of action when it comes to newly synthesized DHEA derivatives. In the case of synthetic compounds it is essential to analyze their 3D structure before testing their binding to possible acceptor sites.

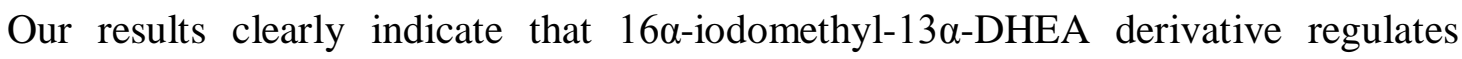
GFAP expression under conditions of reactive gliosis in a different way than DHEA does. It can be concluded that this is due to the epimerization at position 13 of the sterane skeleton, which introduces a bend into the originally planar sterane framework of DHEA. The bent 3D structure of $16 \alpha$-iodomethyl-13 $\alpha$-DHEA compared to DHEA makes it possible that $16 \alpha$ iodomethyl-13 $\alpha$-DHEA might bind to DHEA binding sites with a different affinity, and it might also bind to other sites, where the nearly planar structure of DHEA does not fit. Consequently, it exerts a DHEA-like effect only if binding sites which accept bent 3D structures with high affinity are occupied. On the other hand, the possibility of acting through conversion to unknown metabolites cannot be ruled out. 


\section{Summary}

Recent studies provide increasing number of data indicating the prominent role of estrogens in protecting the nervous system against the noxious consequences of nerve injury. It is also clear that in the process of nerve injury and recovery not only the neurons, but the glial cells are also involved and they are important components of the protective mechanisms. In the present thesis we studied the effect of $17 \beta$-estradiol, testosterone, DHEA, raloxifen and genistein on injury-induced microglia activation in an animal model. Peripheral axotomy of the oculomotor neurons was achieved by the removal of the right eyeball including the extraocular muscles of ovariectomized adult mice. The time course and the extent of microglia activation were followed by the unbiased morphometric analysis of CD11b immunoreactive structures within the oculomotor nucleus.

On the basis of our data we may conclude the following:

1. 17 $\beta$-estradiol attenuates the axotomy induced microglial reaction in the oculomotor nucleus of mice, there is a significant decrease of microglia density 4 days after the injury.

2. DHEA acts in a sexually dimorphic way: in ovariectomized mice it reduced the microglia response, in orchidectomized animals we did not find significant effects.

3. The selective estrogen receptor regulator raloxifen decreased the microglia reactivity, testosterone and the phytoestrogen genistein were ineffective in our model.

4. We have demonstrated the presence of both ER $\alpha$ and $E R \beta$ in the motoneurons of the oculomotor nucleus, the cellular localization of the two receptors is different. No ER receptors were visualized in the microglial cells.

5. By comparing the molecular structure of DHEA and its synthetic derivative $16 \alpha-$ iodomethyl-13 $\alpha$-DHEA we concluded that the altered 3D structure of the sterane framework may be responsible for the difference in action of the two molecules.

Our results show that the microglia response to nerve injury is affected by gonadal steroids and/or neurosteroids, which indicates that the hormonal effects may contribute to 
protective mechanisms resulting in the structural and functional recovery of the nervous system.

The estrogen sensitive activity of microglia may help elucidating the molecular mechanisms involved in the regulation of pro- and anti-inflammatory reactions of the CNS. The better understanding of the influence of estrogen on microglial reactions may render these cells a potential target for the anti-inflammatory use of steroid hormones, i.e. it may open the way to new theoretical approaches in understanding the neurodegenerative processes and neuroprotective mechanisms, as well. 


\section{References}

Akiyama H, McGeer PL (1990) Brain microglia constitutively express beta-2 integrins. J Neuroimmunol 30:81-93.

Akwa Y, Young J, Kabbadj K, Sancho MJ, Zucman D, Vourch C, Jungtestas I, Hu ZY, Legoascogne C, Jo DH, Corpecho C, Simon P, Baulieu EE, Robel P (1991) Neurosteroids - Biosynthesis, Metabolism and Function of Pregnenolone and Dehydroepiandrosterone in the Brain. Journal of Steroid Biochemistry and Molecular Biology 40:71-81.

Alvarez-De-La-Rosa M, Silva I, Nilsen J, Perez MM, Garcia-Segura LM, Avila J, Naftolin F (2005) Estradiol prevents neural Tau hyperphosphorylation characteristic of Alzheimer's disease. Future of Hormone Therapy: What Basic Science and Clinical Studies Teach Us 1052:210-224.

Auci DL, Reading CL, Frincke JM (2009) 7-Hydroxy androstene steroids and a novel synthetic analogue with reduced side effects as a potential agent to treat autoimmune diseases. Autoimmunity Reviews 8:369-372.

Azcoitia I, Moreno A, Carrero P, Palacios S, Garcia-Segura LM (2006) Neuroprotective effects of soy phytoestrogens in the rat brain. Gynecological Endocrinology 22:63-69.

Baker AE, Brautigam VM, Watters JJ (2004) Estrogen modulates microglial inflammatory mediator production via interactions with estrogen receptor beta. Endocrinology 145:5021-5032.

Bal-Price A, Brown GC (2001) Inflammatory neurodegeneration mediated by nitric oxide from activated glia-inhibiting neuronal respiration, causing glutamate release and excitotoxicity. Journal of Neuroscience 21:6480-6491.

Barreto G, Veiga S, Azcoitia I, Garcia-Segura LM, Garcia-Ovejero D (2007) Testosterone decreases reactive astroglia and reactive microglia after brain injury in male rats: role of its metabolites, oestradiol and dihydrotestosterone. Eur J Neurosci 25:3039-3046.

Baulieu EE, Robel P (1996) Dehydroepiandrosterone and dehydroepiandrosterone sulfate as neuroactive neurosteroids. Journal of Endocrinology 150:S221-S239.

Belandia B, Parker MG (2003) Nuclear receptors: A rendezvous for chromatin remodeling factors. Cell 114:277-280.

Bell MD, Perry VH (1995) Adhesion molecule expression on murine cerebral endothelium following the injection of a proinflammagen or during acute neuronal degeneration. $\mathbf{J}$ Neurocytol 24:695-710.

Benvenuti S, Luciani P, Vannelli GB, Gelmini S, Franceschi E, Serio M, Peri A (2005) Estrogen and selective estrogen receptor modulators exert neuroprotective effects and stimulate the expression of selective Alzheimer's disease indicator-1, a recently discovered antiapoptotic gene, in human neuroblast long-term cell cultures. Journal of Clinical Endocrinology \& Metabolism 90:1775-1782.

Beral V, Banks E, Reeves G, Bull D (2003) Breast cancer and hormone-replacement therapy: the Million Women Study - Reply. Lancet 362:1330-1331.

Beyer M, Gimsa U, Eyupoglu IY, Hailer NP, Nitsch R (2000) Phagocytosis of neuronal or glial debris by microglial cells: upregulation of MHC class II expression and multinuclear giant cell formation in vitro. Glia 31:262-266. 
Bjugn R, Gundersen HJ (1993) Estimate of the total number of neurons and glial and endothelial cells in the rat spinal cord by means of the optical disector. J Comp Neurol 328:406-414.

Bruce-Keller AJ, Barger SW, Moss NI, Pham JT, Keller JN, Nath A (2001) Pro-inflammatory and pro-oxidant properties of the HIV protein Tat in a microglial cell line: attenuation by 17 beta-estradiol. Journal of Neurochemistry 78:1315-1324.

Bruce-Keller AJ, Keeling JL, Keller JN, Huang FF, Camondola S, Mattson MP (2000) Antiinflammatory effects of estrogen on microglial activation. Endocrinology 141:3646-3656.

Brzozowski AM, Pike ACW, Dauter Z, Hubbard RE, Bonn T, Engstrom O, Ohman L, Greene GL, Gustafsson JA, Carlquist M (1997) Molecular basis of agonism and antagonism in the oestrogen receptor. Nature 389:753-758.

Cardona-Gomez P, Perez M, Avila J, Garcia-Segura LM, Wandosell F (2004) Estradiol inhibits GSK3 and regulates interaction of estrogen receptors, GSK3, and beta-catenin in the hippocampus. Molecular and Cellular Neuroscience 25:363-373.

Cash E, Rott O (1994) Microglial cells qualify as the stimulators of unprimed CD4+ and CD8+ T lymphocytes in the central nervous system. Clin Exp Immunol 98:313-318.

Chen F, Knecht K, Birzin E, Fisher J, Wilkinson H, Mojena M, Moreno CT, Schmidt A, Harada S, Freedman LP, Reszka AA (2005) Direct agonist/antagonist functions of dehydroepiandrosterone. Endocrinology 146:4568-4576.

Ciriza I, Azcoitia I, Garcia-Segura LM (2004a) Reduced progesterone metabolites protect rat hippocampal neurones from kainic acid excitotoxicity in vivo. J Neuroendocrinol 16:58-63.

Ciriza I, Carrero P, Azcoitia I, Lundeen SG, Garcia-Segura LM (2004b) Selective estrogen receptor modulators protect hippocampal neurons from kainic acid excitotoxicity: Differences with the effect of estradiol. Journal of Neurobiology 61:209-221.

Culmsee C, Vedder H, Ravati A, Junker V, Otto D, Ahlemeyer B, Krieg JC, Krieglstein J (1999) Neuroprotection by estrogens in a mouse model of focal cerebral ischemia and in cultured neurons: Evidence for a receptor-independent antioxidative mechanism. Journal of Cerebral Blood Flow and Metabolism 19:1263-1269.

Davalos D, Grutzendler J, Yang G, Kim JV, Zuo Y, Jung S, Littman DR, Dustin ML, Gan WB (2005) ATP mediates rapid microglial response to local brain injury in vivo. Nat Neurosci 8:752-758.

Diaz H, Lorenzo A, Carrer HF, Caceres A (1992) Time-Lapse Study of Neurite Growth in Hypothalamic Dissociated Neurons in Culture - Sex-Differences and Estrogen Effects. Journal of Neuroscience Research 33:266-281.

Dimayuga FO, Reed JL, Carnero GA, Wang C, Dimayuga ER, Dimayuga VM, Perger A, Wilson ME, Keller JN, Bruce-Keller AJ (2005) Estrogen and brain inflammation: effects on microglial expression of MHC, costimulatory molecules and cytokines. $\mathrm{J}$ Neuroimmunol 161:123-136.

Dorgan JF, Stanczyk FZ, Longcope C, Stephenson HE, Chang L, Miller R, Franz C, Falk RT, Kahle L (1997) Relationship of serum dehydroepiandrosterone (DHEA), DHEA sulfate, and 5-androstene-3 beta, 17 beta-diol to risk of breast cancer in postmenopausal women. Cancer Epidemiology Biomarkers \& Prevention 6:177-181.

Drew PD, Chavis JA (2000) Female sex steroids: effects upon microglial cell activation. J Neuroimmunol 111:77-85. 
Ekdahl CT, Claasen JH, Bonde S, Kokaia Z, Lindvall O (2003) Inflammation is detrimental for neurogenesis in adult brain. Proceedings of the National Academy of Sciences of the United States of America 100:13632-13637.

Ferreira A, Caceres A (1991) Estrogen-Enhanced Neurite Growth - Evidence for A Selective Induction of Tau and Stable Microtubules. Journal of Neuroscience 11:392-400.

Ferrini M, Bisagno V, Piroli G, Grillo C, Deniselle MCG, de Nicola AF (2002) Effects of estrogens on choline-acetyltransferase immunoreactivity and GAP-43 mRNA in the forebrain of young and aging male rats. Cellular and Molecular Neurobiology 22:289301.

Fillit H, Weinreb H, Cholst I, Luine V, McEwen B, Amador R, Zabriskie J (1986) Observations in A Preliminary Open Trial of Estradiol Therapy for Senile DementiaAlzheimers Type. Psychoneuroendocrinology 11:337-345.

Ganter S, Northoff H, Mannel D, Gebicke-Harter PJ (1992) Growth control of cultured microglia. J Neurosci Res 33:218-230.

Garcia-Estrada J, Luquin S, Fernandez AM, Garcia-Segura LM (1999) Dehydroepiandrosterone, pregnenolone and sex steroids down-regulate reactive astroglia in the male rat brain after a penetrating brain injury. International Journal of Developmental Neuroscience 17:145-151.

Garcia-Ovejero D, Azcoitia I, DonCarlos LL, Melcangi RC, Garcia-Segura LM (2005) Glianeuron crosstalk in the neuroprotective mechanisms of sex steroid hormones. Brain Res Brain Res Rev 48:273-286.

Garcia-Segura LM (2008) Aromatase in the brain: Not just for reproduction anymore. Journal of Neuroendocrinology 20:705-712.

Garcia-Segura LM, Azcoitia I, DonCarlos LL (2001) Neuroprotection by estradiol. Progress in Neurobiology 63:29-60.

Garcia-Segura LM, Luquin S, Parducz A, Naftolin F (1994) Gonadal hormone regulation of glial fibrillary acidic protein immunoreactivity and glial ultrastructure in the rat neuroendocrine hypothalamus. Glia 10:59-69.

Garciaestrada J, Delrio JA, Luquin S, Soriano E, Garciasegura LM (1993) Gonadal-Hormones Down-Regulate Reactive Gliosis and Astrocyte Proliferation After A Penetrating Brain Injury. Brain Research 628:271-278.

Genud R, Merenlender A, Gispan-Herman I, Maayan R, Weizman A, Yadid G (2009) DHEA Lessens Depressive-Like Behavior via GABA-ergic Modulation of the Mesolimbic System. Neuropsychopharmacology 34:577-584.

Gibson CL, Gray LJ, Murphy SP, Bath PMW (2006) Estrogens and experimental ischemic stroke: a systematic review. Journal of Cerebral Blood Flow and Metabolism 26:11031113.

Gold SM, Sasidhar MV, Morales LB, Du SM, Sicotte NL, Tiwari-Woodruff SK, Voskuhl RR (2009) Estrogen treatment decreases matrix metalloproteinase (MMP)-9 in autoimmune demyelinating disease through estrogen receptor alpha (ER alpha). Laboratory Investigation 89:1076-1083.

Gold SM, Voskuhl RR (2009) Estrogen treatment in multiple sclerosis. Journal of the Neurological Sciences 286:99-103.

Goodenough S, Schleusner D, Pietrzik C, Skutella T, Behl C (2005) Glycogen synthase kinase 3 beta links neuroprotection by 17 beta-estradiol to key Alzheimer processes. Neuroscience 132:581-589. 
Graeber MB, Streit WJ, Kreutzberg GW (1988) Axotomy of the rat facial nerve leads to increased CR3 complement receptor expression by activated microglial cells. $\mathrm{J}$ Neurosci Res 21:18-24.

Gyenes A, Hoyk Z, Csakvari E, Siklos L, Parducz A (2010) 17 Beta-Estradiol Attenuates Injury-Induced Microglia Activation in the Oculomotor Nucleus. Neuroscience 171:677-682.

Hanisch UK, Kettenmann H (2007) Microglia: active sensor and versatile effector cells in the normal and pathologic brain. Nat Neurosci 10:1387-1394.

Haynes SE, Hollopeter G, Yang G, Kurpius D, Dailey ME, Gan WB, Julius D (2006) The P2Y12 receptor regulates microglial activation by extracellular nucleotides. Nat Neurosci 9:1512-1519.

Heldring N, Pike A, Andersson S, Matthews J, Cheng G, Hartman J, Tujague M, Strom A, Treuter E, Warner M, Gustafsson JA (2007) Estrogen receptors: How do they signal and what are their targets. Physiological Reviews 87:905-931.

Henderson VW, Paganinihill A, Emanuel CK, Dunn ME, Buckwalter JG (1994) Estrogen Replacement Therapy in Older Women - Comparisons Between Alzheimers-Disease Cases and Nondemented Control Subjects. Archives of Neurology 51:896-900.

Hernandez-Pando R, Aguilar-Leon D, Orozco H, Serrano A, Ahlem C, Trauer R, Schramm B, Reading C, Fincke J, Rook GAW (2005) 16 alpha-bromoepiandrosterone restores T helper cell type 1 activity and accelerates chemotherapy-induced bacterial clearance in a model of progressive pulmonary tuberculosis. Journal of Infectious Diseases 191:299-306.

Honjo H, Ogino Y, Naitoh K, Urabe M, Kitawaki J, Yasuda J, Yamamoto T, Ishihara S, Okada H, Yonezawa T, Hayashi K, Nambara T (1989) Invivo Effects by Estrone Sulfate on the Central-Nervous-System Senile Dementia (Alzheimers Type). Journal of Steroid Biochemistry and Molecular Biology 34:521-525.

Hoyk Z, Parducz A, Garcia-Segura LM (2004a) Dehydroepiandrosterone regulates astroglia reaction to denervation of olfactory glomeruli. Glia 48:207-216.

Hoyk Z, Parducz A, Garcia-Segura LM (2004b) Dehydroepiandrosterone regulates astroglia reaction to denervation of olfactory glomeruli. Glia 48:207-216.

Ibrahim AS, El Shishtawy MM, Pena A, Liou GI (2010) Genistein attenuates retinal inflammation associated with diabetes by targeting of microglial activation. Molecular Vision 16:2033-2042.

Islamov RR, Hendricks WA, Jones RJ, Lyall GJ, Spanier NS, Murashov AK (2002) 17 betaEstradiol stimulates regeneration of sciatic nerve in female mice. Brain Research 943:283-286.

Jellinck PH, Croft G, McEwen BS, Gottfried-Blackmore A, Jones G, Byford V, Bulloch K (2005) Metabolism of dehydroepiandrosterone by rodent brain cell lines: relationship between 7-hydroxylation and aromatization. J Steroid Biochem Mol Biol 93:81-86.

Jellinck PH, Lee SJ, McEwen BS (2001) Metabolism of dehydroepiandrosterone by rat hippocampal cells in culture: possible role of aromatization and 7-hydroxylation in neuroprotection. J Steroid Biochem Mol Biol 78:313-317.

Jensen MB, Finsen B, Zimmer J (1997) Morphological and immunophenotypic microglial changes in the denervated fascia dentata of adult rats: correlation with blood-brain barrier damage and astroglial reactions. Exp Neurol 143:103-116.

Jensen MB, Gonzalez B, Castellano B, Zimmer J (1994) Microglial and astroglial reactions to anterograde axonal degeneration: a histochemical and immunocytochemical study of 
the adult rat fascia dentata after entorhinal perforant path lesions. Exp Brain Res 98:245-260.

Jensen MB, Hegelund IV, Poulsen FR, Owens T, Zimmer J, Finsen B (1999) Microglial reactivity correlates to the density and the myelination of the anterogradely degenerating axons and terminals following perforant path denervation of the mouse fascia dentata. Neuroscience 93:507-518.

Johansson T, Le Greves P (2005) The effect of dehydroepiandrosterone sulfate and allopregnanolone sulfate on the binding of [H-3]ifenprodil to the N-methyl-Daspartate receptor in rat frontal cortex membrane. Journal of Steroid Biochemistry and Molecular Biology 94:263-266.

Juhasz-Vedres G, Rozsa E, Rakos G, Dobszay MB, Kis Z, Wolfling J, Toldi J, Parducz A, Farkas T (2006) Dehydroepiandrosterone sulfate is neuroprotective when administered either before or after injury in a focal cortical cold lesion model. Endocrinology 147:683-686.

Kimelberg HK, Jin YQ, Charniga C, Feustel PJ (2003) Neuroprotective activity of tamoxifen in permanent focal ischemia. Journal of Neurosurgery 99:138-142.

Kimonides VG, Khatibi NH, Svendsen CN, Sofroniew MV, Herbert J (1998) Dehydroepiandrosterone (DHEA) and DHEA-sulfate (DHEAS) protect hippocampal neurons against excitatory amino acid-induced neurotoxicity. Proceedings of the National Academy of Sciences of the United States of America 95:1852-1857.

Kipper-Galperin M, Galilly R, Danenberg HD, Brenner T (1999) Dehydroepiandrosterone selectively inhibits production of tumor necrosis factor alpha and interlukin-6 in astrocytes. International Journal of Developmental Neuroscience 17:765-775.

Klinge CM (2000) Estrogen receptor interaction with co-activators and co-repressors. Steroids 65:227-251.

Kreutzberg GW (1996) Microglia: a sensor for pathological events in the CNS. Trends Neurosci 19:312-318.

Kuiper GG, Carlsson B, Grandien K, Enmark E, Haggblad J, Nilsson S, Gustafsson JA (1997) Comparison of the ligand binding specificity and transcript tissue distribution of estrogen receptors alpha and beta. Endocrinology 138:863-870.

Kuiper GG, Enmark E, Pelto-Huikko M, Nilsson S, Gustafsson JA (1996) Cloning of a novel receptor expressed in rat prostate and ovary. Proc Natl Acad Sci U S A 93:5925-5930.

Ladeby R, Wirenfeldt M, Garcia-Ovejero D, Fenger C, Dissing-Olesen L, Dalmau I, Finsen B (2005) Microglial cell population dynamics in the injured adult central nervous system. Brain Res Brain Res Rev 48:196-206.

Laflamme N, Nappi RE, Drolet G, Labrie C, Rivest S (1998) Expression and neuropeptidergic characterization of estrogen receptors (ER alpha and ER beta) throughout the rat brain: Anatomical evidence of distinct roles of each subtype. Journal of Neurobiology 36:357-378.

Lei DL, Long JM, Hengemihle J, O'Neill J, Manaye KF, Ingram DK, Mouton PR (2003) Effects of estrogen and raloxifene on neuroglia number and morphology in the hippocampus of aged female mice. Neuroscience 121:659-666.

Leranth C, Hajszan T, Maclusky NJ (2004) Androgens increase spine synapse density in the CA1 hippocampal subfield of ovariectomized female rats. J Neurosci 24:495-499.

Lobo RA (1995) Estrogen Replacement - the Evolving Role of Alternative Delivery Systems Introduction. American Journal of Obstetrics and Gynecology 173:981. 
Long JM, Kalehua AN, Muth NJ, Calhoun ME, Jucker M, Hengemihle JM, Ingram DK, Mouton PR (1998) Stereological analysis of astrocyte and microglia in aging mouse hippocampus. Neurobiol Aging 19:497-503.

Lorenzo A, Diaz H, Carrer H, Caceres A (1992) Amygdala Neurons Invitro - Neurite Growth and Effects of Estradiol. Journal of Neuroscience Research 33:418-435.

Lustig RH, Sudol M, Pfaff DW, Federoff HJ (1991) Estrogenic Regulation and Sex Dimorphism of Growth-Associated Protein 43-Kda (Gap-43) Messenger-Rna in the Rat. Molecular Brain Research 11:125-132.

MacLennan AH, Henderson VW, Paine BJ, Mathias J, Ramsay EN, Ryan P, Stocks NP, Taylor AW (2006) Hormone therapy, timing of initiation, and cognition in women aged older than 60 years: the REMEMBER pilot study. Menopause-the Journal of the North American Menopause Society 13:28-36.

Maclusky NJ, Luine VN, Hajszan T, Leranth C (2005) The 17alpha and 17beta isomers of estradiol both induce rapid spine synapse formation in the CA1 hippocampal subfield of ovariectomized female rats. Endocrinology 146:287-293.

Maggi A, Vegeto E, Brusadelli A, Belcredito S, Pollio G, Ciana P (2000) Identification of estrogen target genes in human neural cells. J Steroid Biochem Mol Biol 74:319-325.

Marchetti B, Abbracchio MP (2005) To be or not to be (inflamed) - is that the question in anti-inflammatory drug therapy of neurodegenerative disorders? Trends in Pharmacological Sciences 26:517-525.

Marchetti B, Kettenmann H, Streit WJ (2005) Glia-Neuron Crosstalk in Neuroinflammation, Neurodegeneration and Neuroprotection - Introduction. Brain Research Reviews 48:129-132.

Marotta F, Mao GS, Liu T, Chui DH, Lorenzetti A, Xiao Y, Marandola P (2006) Antiinflammatory and neuroprotective effect of a phytoestrogen compound on rat microglia. Estrogens and Human Diseases 1089:276-281.

Matsumoto A, Arai Y (1979) Synaptogenic effect of estrogen on the hypothalamic arcuate nucleus of the adult female rat. Cell Tissue Res 198:427-433.

Matsumoto A, Arai Y (1981) Neuronal plasticity in the deafferented hypothalamic arcuate nucleus of adult female rats and its enhancement by treatment with estrogen. J Comp Neurol 197:197-205.

Matsumoto A, Murakami S, Arai Y (1985) Estrogen Facilitates Synaptogenesis in the Neonatal Preoptic Area Grafted Into the Adult Brain. Zoological Science 2:985.

McEwen B (2002) Estrogen action throughout the brain. Recent Progress in Hormone Research 57:357-384.

McKenna NJ, O'Malley BW (2002) Combinatorial control of gene expression by nuclear receptors and coregulators. Cell 108:465-474.

McNaught KSP, Jenner P (1999) Altered glial function causes neuronal death and increases neuronal susceptibility to 1-methyl-4-phenylpyridinium- and 6-hydroxydopamineinduced toxicity in astrocytic/ventral mesencephalic co-cultures. Journal of Neurochemistry 73:2469-2476.

Mehta SH, Dhandapani KM, De Sevilla LM, Webb RC, Mahesh VB, Brann DW (2003) Tamoxifen, a selective estrogen receptor modulator, reduces ischemic damage caused by middle cerebral artery occlusion in the ovariectomized female rat. Neuroendocrinology 77:44-50.

Minutolo F, Bertini S, Granchi C, Marchitiello T, Prota G, Rapposelli S, Tuccinardi T, Martinelli A, Gunther JR, Carlson KE, Katzenellenbogen JA, Macchia M (2009) 
Structural Evolutions of Salicylaldoximes as Selective Agonists for Estrogen Receptor beta. Journal of Medicinal Chemistry 52:858-867.

Mor G, Nilsen J, Horvath T, Bechmann I, Brown S, Garcia-Segura LM, Naftolin F (1999) Estrogen and microglia: A regulatory system that affects the brain. J Neurobiol 40:484-496.

Morales AJ, Nolan JJ, Nelson JC, Yen SSC (1994) Effects of Replacement Dose of Dehydroepiandrosterone in Men and Women of Advancing Age. Journal of Clinical Endocrinology \& Metabolism 78:1360-1367.

Morse JK, Dekosky ST, Scheff SW (1992) Neurotrophic Effects of Steroids on LesionInduced Growth in the Hippocampus. 2. Hormone Replacement. Experimental Neurology 118:47-52.

Morse JK, Scheff SW, Dekosky ST (1986) Gonadal-Steroids Influence Axon Sprouting in the Hippocampal Dentate Gyrus - A Sexually Dimorphic Response. Experimental Neurology 94:649-658.

Mouton PR, Long JM, Lei DL, Howard V, Jucker M, Calhoun ME, Ingram DK (2002) Age and gender effects on microglia and astrocyte numbers in brains of mice. Brain Res 956:30-35.

Nelson HD, Humphrey LL, Nygren P, Teutsch SM, Allan JD (2002) Postmenopausal hormone replacement therapy - Scientific review. Jama-Journal of the American Medical Association 288:872-881.

Nimmerjahn A, Kirchhoff F, Helmchen F (2005) Resting microglial cells are highly dynamic surveillants of brain parenchyma in vivo. Science 308:1314-1318.

Nolte C, Moller T, Walter T, Kettenmann H (1996) Complement 5a controls motility of murine microglial cells in vitro via activation of an inhibitory G-protein and the rearrangement of the actin cytoskeleton. Neuroscience 73:1091-1107.

Norris JD, Paige LA, Christensen DJ, Chang CY, Huacani MR, Fan DJ, Hamilton PT, Fowlkes DM, McDonnell DP (1999) Peptide antagonists of the human estrogen receptor. Science 285:744-746.

Oestreicher AB, De Graan PNE, Gispen WH, Verhaagen J, Schrama LH (1997) B-50, the growth associated protein-43: Modulation of cell morphology and communication in the nervous system. Progress in Neurobiology 53:627-686.

Olesen J, Gustavsson A, Svensson M, Wittchen HU, Jonsson B (2012) The economic cost of brain disorders in Europe. European Journal of Neurology 19:155-162.

Paganinihill A, Henderson VW (1994) Estrogen Deficiency and Risk of Alzheimers-Disease in Women. American Journal of Epidemiology 140:256-261.

Paige LA, Christensen DJ, Gron H, Norris JD, Gottlin EB, Padilla KM, Chang CY, Ballas LM, Hamilton PT, McDonnell DP, Fowlkes DM (1999) Estrogen receptor (ER) modulators each induce distinct conformational changes in ER alpha and ER beta. Proceedings of the National Academy of Sciences of the United States of America 96:3999-4004.

Paizs M, Engelhardt JI, Siklos L (2009) Quantitative assessment of relative changes of immunohistochemical staining by light microscopy in specified anatomical regions. J Microsc 234:103-112.

Parducz A, Perez J, Garcia-Segura LM (1993) Estradiol induces plasticity of gabaergic synapses in the hypothalamus. Neuroscience 53:395-401.

Pedersen NC, North TW, Rigg R, Reading C, Higgins J, Leutenegger C, Henderson GL (2003) 16alpha-Bromo-epiandrosterone therapy modulates experimental feline 
immunodeficiency virus viremia: initial enhancement leading to long-term suppression. Vet Immunol Immunopathol 94:133-148.

Perez-Neri I, Montes S, Ojeda-Lopez C, Ramirez-Bermudez J, Rios C (2008) Modulation of neurotransmitter systems by dehydroepiandrosterone and dehydroepiandrosterone sulfate: Mechanism of action and relevance to psychiatric disorders. Progress in Neuro-Psychopharmacology \& Biological Psychiatry 32:1118-1130.

Perry VH, Gordon S (1987) Modulation of CD4 antigen on macrophages and microglia in rat brain. J Exp Med 166:1138-1143.

Perry VH, Hume DA, Gordon S (1985) Immunohistochemical localization of macrophages and microglia in the adult and developing mouse brain. Neuroscience 15:313-326.

Resnick SM, Maki PM, Rapp SR, Espeland MA, Brunner R, Coker LH, Granek IA, Hogan P, Ockene JK, Shumaker SA (2006) Effects of combination estrogen plus progestin hormone treatment on cognition and affect. Journal of Clinical Endocrinology \& Metabolism 91:1802-1810.

Schneider LS, Farlow MR, Henderson VW, Pogoda JM (1996) Effects of estrogen replacement therapy on response to tacrine in patients with Alzheimer's disease. Neurology 46:1580-1584.

Schwartz J, Freeman R, Frishman W (1995) Clinical-Pharmacology of Estrogens Cardiovascular Actions and Cardioprotective Benefits of Replacement Therapy in Postmenopausal Women. Journal of Clinical Pharmacology 35:1-16.

Schwarz JM, Sholar PW, Bilbo SD (2012) Sex differences in microglial colonization of the developing rat brain. Journal of Neurochemistry 120:948-963.

Shughrue PJ, Dorsa DM (1993) Estrogen Modulates the Growth-Associated Protein Gap-43 (Neuromodulin) Messenger-Rna in the Rat Preoptic Area and Basal Hypothalamus. Neuroendocrinology 57:439-447.

Singer CA, Pang PA, Dobie DJ, Dorsa DM (1996) Estrogen increases GAP-43 (Neuromodulin) mRNA in the preoptic area of aged rats. Neurobiology of Aging 17:661-663.

Stence N, Waite M, Dailey ME (2001) Dynamics of microglial activation: a confocal timelapse analysis in hippocampal slices. Glia 33:256-266.

Stone DJ, Rozovsky I, Morgan TE, Anderson CP, Hajian H, Finch CE (1997) Astrocytes and microglia respond to estrogen with increased apoE mRNA in vivo and in vitro. Exp Neurol 143:313-318.

Streit WJ (2002) Microglia as neuroprotective, immunocompetent cells of the CNS. Glia 40:133-139.

Streit WJ, Conde JR, Fendrick SE, Flanary BE, Mariani CL (2005) Role of microglia in the central nervous system's immune response. Neurol Res 27:685-691.

Streit WJ, Graeber MB, Kreutzberg GW (1989) Peripheral nerve lesion produces increased levels of major histocompatibility complex antigens in the central nervous system. $\mathbf{J}$ Neuroimmunol 21:117-123.

Suuronen T, Nuutinen T, Huuskonen J, Ojala J, Thornell A, Salminen A (2005) Antiinflammatory effect of selective estrogen receptor modulators (SERMs) in microglial cells. Inflammation Research 54:194-203.

Tang MX, Jacobs D, Stern Y, Marder K, Schofield P, Gurland B, Andrews H, Mayeux R (1996) Effect of oestrogen during menopause on risk and age at onset of Alzheimer's disease. Lancet 348:429-432. 
Tanzer L, Jones KJ (1997) Gonadal steroid regulation of hamster facial nerve regeneration: Effects of dihydrotestosterone and estradiol. Experimental Neurology 146:258-264.

Tapia-Gonzalez S, Carrero P, Pernia O, Garcia-Segura LM, Diz-Chaves Y (2008) Selective oestrogen receptor (ER) modulators reduce microglia reactivity in vivo after peripheral inflammation: potential role of microglial ERs. J Endocrinol 198:219-230.

Tiwari-Woodruff S, Morales LBJ, Lee R, Voskuhl RR (2007a) Differential neuroprotective and anti inflammatory effects of estrogen receptor (ER)alpha and ER beta ligand treatment. Proceedings of the National Academy of Sciences of the United States of America 104:14813-14818.

Tiwari-Woodruff SK, Morales LB, Lee RR, Voskuhl RR (2007b) Differential neuroprotective and anti-inflammatory effects of estrogen receptor ligands. Journal of Neurochemistry 102:140.

Tomas-Camardiel M, Sanchez-Hidalgo MC, Sanchez del Pino MJ, Navarro A, Machado A, Cano J (2002) Comparative study of the neuroprotective effect of dehydroepiandrosterone and 17beta-estradiol against 1-methyl-4-phenylpyridium toxicity on rat striatum. Neuroscience 109:569-584.

Turgeon JL, Carr MC, Maki PM, Mendelsohn ME, Wise PM (2006) Complex actions of sex steroids in adipose tissue, the cardiovascular system, and brain: Insights from basic science and clinical studies. Endocrine Reviews 27:575-605.

Tworoger SS, Missmer SA, Eliassen AH, Spiegelman D, Folkerd E, Dowsett M, Barbieri RL, Hankinson SE (2006) The association of plasma DHEA and DHEA sulfate with breast cancer risk in predominantly premenopausal women. Cancer Epidemiology Biomarkers \& Prevention 15:967-971.

Vegeto E, Belcredito S, Etteri S, Ghisletti S, Brusadelli A, Meda C, Krust A, Dupont S, Ciana P, Chambon P, Maggi A (2003) Estrogen receptor-alpha mediates the brain antiinflammatory activity of estradiol. Proc Natl Acad Sci U S A 100:9614-9619.

Vegeto E, Belcredito S, Ghisletti S, Meda C, Etteri S, Maggi A (2006) The endogenous estrogen status regulates microglia reactivity in animal models of neuroinflammation. Endocrinology 147:2263-2272.

Vegeto E, Bonincontro C, Pollio G, Sala A, Viappiani S, Nardi F, Brusadelli A, Viviani B, Ciana P, Maggi A (2001) Estrogen prevents the lipopolysaccharide-induced inflammatory response in microglia. J Neurosci 21:1809-1818.

Vegeto E, Pollio G, Ciana P, Maggi A (2000) Estrogen blocks inducible nitric oxide synthase accumulation in LPS-activated microglia cells. Exp Gerontol 35:1309-1316.

Vegeto E, Pollio G, Pellicciari C, Maggi A (1999) Estrogen and progesterone induction of survival of monoblastoid cells undergoing TNF-alpha-induced apoptosis. FASEB J 13:793-803.

Walf AA, Frye CA (2007) Estradiol decreases anxiety behavior and enhances inhibitory avoidance and gestational stress produces opposite effects. Stress-the International Journal on the Biology of Stress 10:251-260.

Wang MJ, Huang HM, Chen HL, Jeng KCG (2001) Dehydroepiandrosterone inhibits lipopolysaccharide-induced nitric oxide production in BV-2 microglia. Journal of Neurochemistry 77:830-838.

Wang XJ, Chen SD, Ma GZ, Ye M, Lu GQ (2005) Genistein protects dopaminergic neurons by inhibiting microglial activation. Neuroreport 16:267-270.

Young EA, Kornstein SG, Harvey AT, Wisniewski SR, Barkin J, Fava M, Trivedi MH, Rush AJ (2007) Influences of hormone-based contraception on depressive symptoms in 
premenopausal women with major depression. Psychoneuroendocrinology 32:843853.

Zhang L, Li BS, Zhao WQ, Chang YH, Ma W, Dragan M, Barker JL, Hu Q, Rubinow DR (2002) Sex-related differences in MAPKs activation in rat astrocytes: effects of estrogen on cell death. Molecular Brain Research 103:1-11.

Zhao LQ, O'Neill K, Brinton RD (2005) Selective estrogen receptor modulators (SERMs) for the brain: Current status and remaining challenges for developing NeuroSERMs. Brain Research Reviews 49:472-493.

Zhao LQ, O'Neill K, Brinton RD (2006) Estrogenic agonist activity of ICI 182,780 (Faslodex) in hippocampal neurons: Implications for basic science understanding of estrogen signaling and development of estrogen modulators with a dual therapeutic profile. Journal of Pharmacology and Experimental Therapeutics 319:1124-1132.

Zou LB, Yamada K, Sasa M, Nakata Y, Nabeshima T (2000) Effects of sigma(1) receptor agonist SA4503 and neuroactive steroids on performance in a radial arm maze task in rats. Neuropharmacology 39:1617-1627.

Zwain IH, Yen SSC (1999) Dehydroepiandrosterone: Biosynthesis and metabolism in the brain. Endocrinology 140:880-887. 


\section{Acknowledgements}

This thesis is the result of work and study in the Institute of Biophysics, Biological Research Center of the Hungarian Academy of Sciences. During my stay in Szeged I was accompanied and supported by many people whom I wish to acknowledge now.

First of all, I would like to express my deepest gratitude to my supervisor, Dr. Árpád Párducz, who introduced me to the field of neurobiology. During my whole Ph.D. student period I was impressed and got inspired by his way of thinking about science and life. His careful guidance developed my experimental skills and our everyday debates about the projects broadened my knowledge and made my work easy.

I would like to thank his support to Dr. László Siklós the head of the Molecular Neurobiology Group in the Institute of Biophysics, Biological Research Center and to all the members of the group and the institute for creating the stimulating atmosphere and giving interesting feedbacks and valuable discussions.

I am especially grateful for Dr. Zsófia Hoyk to her guidance and helpful comments to improve my thesis.

Special thanks go to my family for their support and love, and to all of my friends who were with me during this period. 
8. Appendix 